\title{
Integrative description of two new species of Malagasy chirping giant pill-millipedes, genus Sphaeromimus (Diplopoda: Sphaerotheriida: Arthrosphaeridae)
}

\author{
Leif MORITZ ${ }^{1, *} \&$ Thomas WESENER ${ }^{2}$ \\ 1,2 Zoologisches Forschungsmuseum Alexander Koenig, Leibniz Institute for Animal Biodiversity, \\ Adenauerallee 160, D-53113 Bonn, Germany. \\ * Corresponding author: moritz.leif@gmail.com \\ 22Email: t.wesener@zfmk.de \\ ${ }^{1}$ urn:lsid:zoobank.org:author:89921EE8-F015-4FED-AB5C-1D17F2C2F8F6 \\ ${ }^{2}$ urn:lsid:zoobank.org:author:86DEA7CD-988C-43EC-B9D6-C51000595B47
}

\begin{abstract}
The species-rich giant pill-millipedes (Sphaerotheriida) often represent a microendemic component of Madagascar's mega-invertebrate fauna. Of the chirping genus Sphaeromimus de Saussure \& Zehntner, 1902, ten species have been described. Here, we describe two new species of Sphaeromimus integratively, combining light microscopy, scanning electron microscopy, DNA barcoding and micro-CT technology for the first time in a taxonomic description of a giant pillmillipede. S. kalambatritra sp. nov. and S. midongy sp. nov. are the first giant pill-millipedes collected and described from the mountainous rainforests of Kalambatritra and Midongy. Both species show island gigantism compared to their congeners. Our analysis of the mitochondrial COI gene shows that the two species are related to one another with a moderate genetic distance $(9.4 \%)$, while they are more closely related to an undetermined specimen from the forest of Vevembe (6.3\% and 8.4\%). They stand in a basal position with S. ivohibe Wesener, 2014 and S. musicus (de Saussure \& Zehntner, 1897). The four aforementioned species share a high number of stridulation ribs on the male harp. Our microCT analysis provides a look into the head of $S$. kalambatritra sp. nov. and shows that non-destructive CT methods are a useful tool for studying the inner morphology of giant pill-millipedes.
\end{abstract}

Keywords. Biodiversity, COI, island gigantism, Kalambatritra, Midongy.

Moritz L. \& Wesener T. 2017. Integrative description of two new species of Malagasy chirping giant pillmillipedes, genus Sphaeromimus (Diplopoda: Sphaerotheriida: Arthrosphaeridae). European Journal of Taxonomy 381: 1-25. https://doi.org/10.5852/ejt.2017.381

\section{Introduction}

Madagascar, the world's $4^{\text {th }}$ largest island, lies in the Indian Ocean east of Africa and has a tropical climate (Moat \& Smith 2007). While its center and west is mainly covered by dry savanna and dry forest, its east is covered by dense humid rainforests (Moat \& Smith 2007). Madagascar is considered one of the world's hottest biodiversity hotspots (Myers et al. 2000; Ganzhorn et al. 2001) and provides shelter to a high 
diversity of endemic species. This high degree of endemism is probably due to its early isolation from Africa more than 150 Ma years ago and from India more than 80 Ma years ago (Wells 2003). Thus 99\% of the amphibian species (Glaw \& Verdes 2003) and 90\% of all species of reptiles (Raxworthy 2003) and mammals (Goodman et al. 2003) in Madagascar are endemic. Since the arrival of humans ca 2000 years ago (Dewar \& Wright 1993), the landscape of Madagascar has undergone tremendous changes resulting in only $9.9 \%$ of the primary vegetation remaining (Myers et al. 2000). A key thread to Madagascar's biodiversity is the fast rate of deforestation of habitat (Harper et al. 2007). Although several projects and action plans were established in the last decades to protect Madagascar's rich nature, deforestation and fragmentation still takes place at an increasing rate (Horning 2012; Waeber et al. 2016). Thus, from 1950 to 2000 the area covered by forests decreased by $40 \%$ (Green \& Sussman 1990).

One of the highly endemic faunal groups of Madagascar are the millipedes, class Diplopoda (Enghoff 2003). Millipedes play an important role in terrestrial ecosystems as detritivores (Cárcamo et al. 2000) and were among the first terrestrial animals, with fossils dating back to the middle Silurian (Shear \& Edgecombe 2010). Sixteen extant orders of Diplopoda are known (Blanke \& Wesener 2014), of which eight occur naturally on Madagascar (Shelley \& Golovatch 2011), with two of them, Polyzoniida (Wesener 2014a) and Siphonophorida (Wesener 2014b), being only recently recorded from the island. Madagascar is host to some of the most spectacular millipedes: different genera of large-bodied pitchblack/bloodred so called "Fire-Millipedes" of the order Spirobolida (Wesener et al. 2009a, 2009b, 2011), as well as the world's largest giant pill-millipedes, order Sphaerotheriida (see Wesener \& Wägele 2008; Wesener 2009), showing island gigantism. All giant pill-millipedes of Madagascar belong to the family Arthrosphaeridae, otherwise only found in India (Wesener \& VandenSpiegel 2009; Wesener et al. 2010) and are an example of the interesting biogeographical history of the Malagasy fauna. All species of the family are characterized by unique stridulation organs present in both sexes (see also Wesener 2014c), the male harp and the female washboard. On Madagascar, three genera with altogether 77 species of Arthrosphaeridae, all endemic, can be found (Wesener 2016): the species-rich genus Zoosphaerium Pocock, 1895, the dwarfed species of the genus Microsphaerotherium Wesener \& VandenSpiegel, 2007 and the genus Sphaeromimus, whose members have especially well-developed stridulation organs (Wesener \& Sierwald 2005). Until 2005 only known from a single specimen, Sphaeromimus was thought to be based on a mislabeled Indian specimen (Jeekel 1999), but then two new species and many specimens were described from SE Madagascar (Wesener \& Sierwald 2005). Morphological (Wesener \& VandenSpiegel 2009) and molecular (Wesener et al. 2010) studies suggest that Sphaeromimus is more closely related to the Indian genus Arthrosphaera Pocock, 1895 than to the other genera in Madagascar. Seven additional species were described integratively in 2014, including the first gigantic species of the genus, reaching the size of a ping-pong ball (Wesener et al. 2014). All specimens found so far are from south and south-east Madagascar (Wesener 2016), and inhabit humid lowland, littoral, or montane rainforests, apart from a single species (S. musicus (Saussure \& Zehntner, 1897)) which is widespread in the spiny forest ecosystem.

Here, we describe two new species of the genus Sphaeromimus, both of them "giants". The species come from previously unsampled regions, the quite remote (only approachable via a hike of $>30 \mathrm{~km}$ ) uniquely transitional forest of Kalambatritra (Irwin et al. 2001) and its nearest neighbour, the eastern montane rainforest of Midongy-Sud (Bora et al. 2007). We chose to describe both species integratively (Padial et al. 2010), using drawings and scanning-electron microscopy (Oatley et al. 1966) combined with genetic barcoding (Hebert et al. 2003; Hebert \& Gregory 2005). For only the second time in Diplopoda taxonomy (Akkari et al. 2015), we also use micro-CT technology (Ritman 2004) to study and visualize internal structures non-invasively. 


\title{
Material and methods
}

\author{
Abbreviations: \\ CAS $=$ California Academy of Sciences, San Francisco, USA \\ FMNH $=$ Field Museum of Natural History, Chicago, USA \\ ZFMK $=$ Zoologisches Forschungsmuseum Alexander Koenig, Leibniz Institute of Terrestrial \\ Biodiversity, Bonn, Germany
}

\section{Specimen collection and conservation}

The described specimens of Sphaeromimus were all obtained from natural history collections and collected by hand during general inventory programs by American museums. The single specimen of the species collected in Midongy (S. midongy sp. nov.) by V. Soramalaia in February 2008, was provided by the FMNH. The four specimens from Kalambatritra (S. kalambatritra sp. nov.; Fig. 2A), collected by B.L. Fisher and colleagues in February 2009, are from the collection of the CAS.

\section{Dissection and illustrations}

The left or the right $1^{\text {st }}, 2^{\text {nd }}$ and $9^{\text {th }}$ legs, the anterior and the posterior telopods of the male holotype, and the left or right $2^{\text {nd }}$ leg and the subanal plate of female paratypes (if present) were dissected for drawings. Pencil-drawings were made using a camera lucida mounted on a Zeiss Discovery V8 (Carl Zeiss AG). For both species the antennae and a part of the endotergum of a mid-body segment were dissected for SEM-imaging. From the species found in Kalambatritra, where more specimens were available, the mandible and the gnathochilarium were dissected as well. All objects were dehydrated in an alcohol series $(96 \%, 96 \%, 100 \%)$ and dried overnight. The parts were mounted on stubs and sputter-coated with gold. Objects were removed from the stubs and returned to alcohol after study. SEM-images were obtained with a Supra VR 300VP scanning electron microscope (Carl Zeiss AG) using the SmartSEM V05.00 software (Carl Zeiss AG).

\section{Micro-CT imaging}

For a non-invasive visualization of internal structures a micro-CT-scan was performed. The head of the female paratype of $S$. kalambatritra sp. nov. was dehydrated via an ascending ethanol series $(96 \%$, $100 \%$ ) and critical point dried. A micro-CT-scan was conducted using the SKYSCAN 1272 microCT-scanner (Brucker microCT, Kontich, Belgium) and the accompanying Control Software v. 1.1.7 (Brucker microCT) with the following settings: source voltage $=60 \mathrm{kV}$, source current $=166 \mu \mathrm{A}$, exposure $=915 \mathrm{~ms}$, rotation of $180^{\circ}$ in rotation steps of $0.2^{\circ}$, frame averaging $=6$, random movement $=$ 15 , flat field correction $\mathrm{ON}$, geometrical correction $\mathrm{ON}$, filter $=\mathrm{Al} 0.25 \mathrm{~mm}$. Reconstruction and thermal drift correction was performed in NRecon v. 1.7.0.4 (Brucker microCT) and the images were converted to 8 bit grayscale images via Fiji ImageJ v. 1.49k (Schindelin et al. 2012). Volume rendering of the dataset for three-dimensional exploration and visualization was done in Drishti v. 2.6.3 (Limaye 2012). The tentorium and nebententorium were segmented automatically and corrected manually in ITK-SNAP v. 3.4.0 (Yushkevich et al. 2006).

\section{DNA-extraction and sequencing}

Muscle tissue was taken from the male holotypes stored in $80 \%$ ethanol and transferred to $95 \%$ ethanol. For DNA extraction the DNeasy Blood \& Tissue Kit (Qiagen Sample \& Assay Technologies) was used. A fragment of the cytochrome $c$ oxidase subunit I (CO1) mitochondrial gene was amplified with the primers HCO2198-JJ and LCO1490-JJ (Astrin \& Stüben 2008) using the Multiplex PCR Kit (Qiagen Sample \& Assay Technologies) and the Thermocycler Biometra TRIO (Biometra GmbH). The PCR protocol and other methods are the same as those used in earlier studies (Wesener 2015). The PCRproduct was enzymatically purified with the Illustra ExoProStar PCR and Sequence Reaction Clean- 
Table 1. Samples of species of Sphaeromimus de Saussure \& Zehntner, 1902, depository, locality, Genbank code, and reliability of the taxonomic identification of the sampled specimen (GenSeq). Genbank numbers marked by asterisk (*) were published in previous studies (Wesener et al. 2010, 2014).

\begin{tabular}{|c|c|c|c|c|}
\hline Species & Specimen Catalog \# & Locality & Genbank \# & GenSeq \\
\hline Procyliosoma leae ${ }^{*}$ & QVMAG 23:45801 & Tasmania & FJ409910* & genseq-4 \\
\hline Zoosphaerium nерtuпus * & FMNH-INS 56005 & Madagascar, Andasibe & FJ409929* & genseq-4 \\
\hline Z. alluaudi ${ }^{*}$ & FMNH-INS 56000 & Madagascar, Petriky & FJ409926* & genseq-3 \\
\hline Arthrosphaera brandtii * & FMNH-INS 8650 & Tanzania, Usambara Hills & FJ409915* & genseq-4 \\
\hline S. musicus $01^{*}$ & FMNH-INS 56016 & Madagascar, Andrahomana & FJ409919* & genseq-4 \\
\hline S. musicus $02 *$ & FMNH-INS 56016 & Madagascar, Andrahomana & FJ409920* & genseq- 4 \\
\hline S. musicus $03^{*}$ & FMNH-INS 56008 & Madagascar, Mangatsiaka & FJ409921* & genseq-4 \\
\hline S. musicus $04^{*}$ & FMNH-INS 56212 & Madagascar, Tsimelahy & FJ409922* & genseq-4 \\
\hline S. musicus 05 (red)* & ZFMK MYR 2273 & Madagascar, Tsimelahy & KJ13244* & genseq-4 \\
\hline S. musicus 06 (red)* & ZFMK MYR 2276 & Madagascar, Tsimelahy & KJ1 & genseq-4 \\
\hline S. splendidus A* & FMNH-INS 6702 & Madagascar, Sainte Luce S9 & FJ40 & genseq-3 \\
\hline S. splendidus $\mathrm{B}^{*}$ & FMNH-INS 56031 & Madagascar, Sainte Luce S9 & FJ4 & genseq-3 \\
\hline S. inexpectatus $\mathrm{A}^{*}$ & FMNH-INS 56033 & Madagascar, Enato & FJ409 & genseq-4 \\
\hline S. inexpectatus B* & FMNH-INS 61090 & Madagascar, Enato & KJ13246* & genseq-4 \\
\hline S. titanus* & CASENT 9032789 & Madagascar, Manombo & KJ13247* & genseq-1 \\
\hline S. ivohibe* & FMNH-INS 8184 & Madagascar, Ivohibe & KJ13248* & genseq-1 \\
\hline S. lavasoa $\mathrm{B}^{*}$ & FMNH-INS 61143 & Madagascar, Gr. Lavasoa & KJ13249* & genseq-2 \\
\hline S. lavasoa $\mathrm{C}^{*}$ & FMNH-INS 61142 & Madagascar, Gr. Lavasoa & KJ13250* & genseq-2 \\
\hline S. andohahela $01 *$ & FMNH-INS 61135 & Madagascar, Isaka-Ivondro & KJ13251* & genseq-2 \\
\hline S. andohahela $02^{*}$ & FMNH-INS 61137 & Madagascar, Isaka-Ivondro & KJ13252* & genseq-2 \\
\hline S. andohahela $03^{*}$ & ZFMK MYR 2322 & Madagascar, Isaka-Ivondro & KJ13253* & genseq-1 \\
\hline S. andohahela $04^{*}$ & FMNH-INS 61136 & Madagascar, Isaka-Ivondro & KJ13254* & genseq-2 \\
\hline S. andohahela $05^{*}$ & FMNH-INS 61132 & Madagascar, Manantantely & KJ13255* & genseq-4 \\
\hline S. andohahela $06^{*}$ & FMNH-INS 61138 & Madagascar, Manantantely & KJ13256* & genseq-4 \\
\hline S. andohahela $07^{*}$ & FMNH-INS 56210 & Madagascar, Malio & FJ409923* & genseq-4 \\
\hline S. andohahela $08^{*}$ & FMNH-INS 56210 & Madagascar, Malio & KJ13257* & genseq-4 \\
\hline S. andohahela $09^{*}$ & ZFMK MYR 2323 & Madagascar, Malio & KJ13258* & genseq-4 \\
\hline S. saintelucei* & ZFMK MYR 889 & Madagascar, Sainte Luce S8 & KJ13259* & genseq-1 \\
\hline S. andrahomana Cave* & FMNH-INS 56211 & Madagascar, Andrahomana & FJ409924* & genseq-4 \\
\hline S. andrahomana* & FMNH-INS 56214 & Madagascar, Ankapaky Plateau & KJ13260* & genseq-1 \\
\hline S. sp. ,Vevembe “* & CASENT 9032816 & Madagascar, Vevembe & KJ13261* & genseq-4 \\
\hline S. kalambatritra sp. 1 & CASENT 9068297-A & Madagascar, Kalambatritra & KY417112 & genseq-1 \\
\hline S. midongy sp. nov. & FMNH-INS 3119888 & Madagascar, Midongy-Befotaka & KY417113 & genseq-1 \\
\hline
\end{tabular}

up Kit (GE Healthcare Life Sciences). Double-strand Sanger sequencing (Sanger et al. 1977) of the cleaned PCR product was performed by Macrogen, Netherlands. Sequences were concatenated using Seqman (DNASTAR Inc.). BLAST searches (Altschul et al. 1990) were used to check the sequences for contaminations. Sequences were translated into amino acids to rule out the accidental amplification of pseudogenes. New sequences were uploaded to Genbank (see Table 1).

\section{Sequence processing and DNA-analysis}

Sequences were aligned by hand in Bioedit (Hall 1999). The final dataset consisted of 33 sequences for 15 species; two of the sequences were newly sequenced and 31 obtained from GenBank (see Table 1), which had been part of two earlier studies (Wesener et al. 2010, 2014). The final dataset included 33 sequences with 674 positions. Distance analysis was performed in Mega 6 (Tamura et al. 2013) using the uncorrected p-distance model. Variation among sites was modeled with gamma distribution with shape parameter $=1$. Included were codon positions $1^{\text {st }}+2^{\text {nd }}+3^{\text {rd }}$. Genetic distances are displayed 
Table 2. Genetic p-distances between species of Sphaeromimus de Saussure \& Zehntner, 1902. Variation among sites was modeled with gamma distribution with shape parameter $=1$. Included were codon positions $1^{\text {st }}+2^{\text {nd }}+3^{\text {rd }}$.

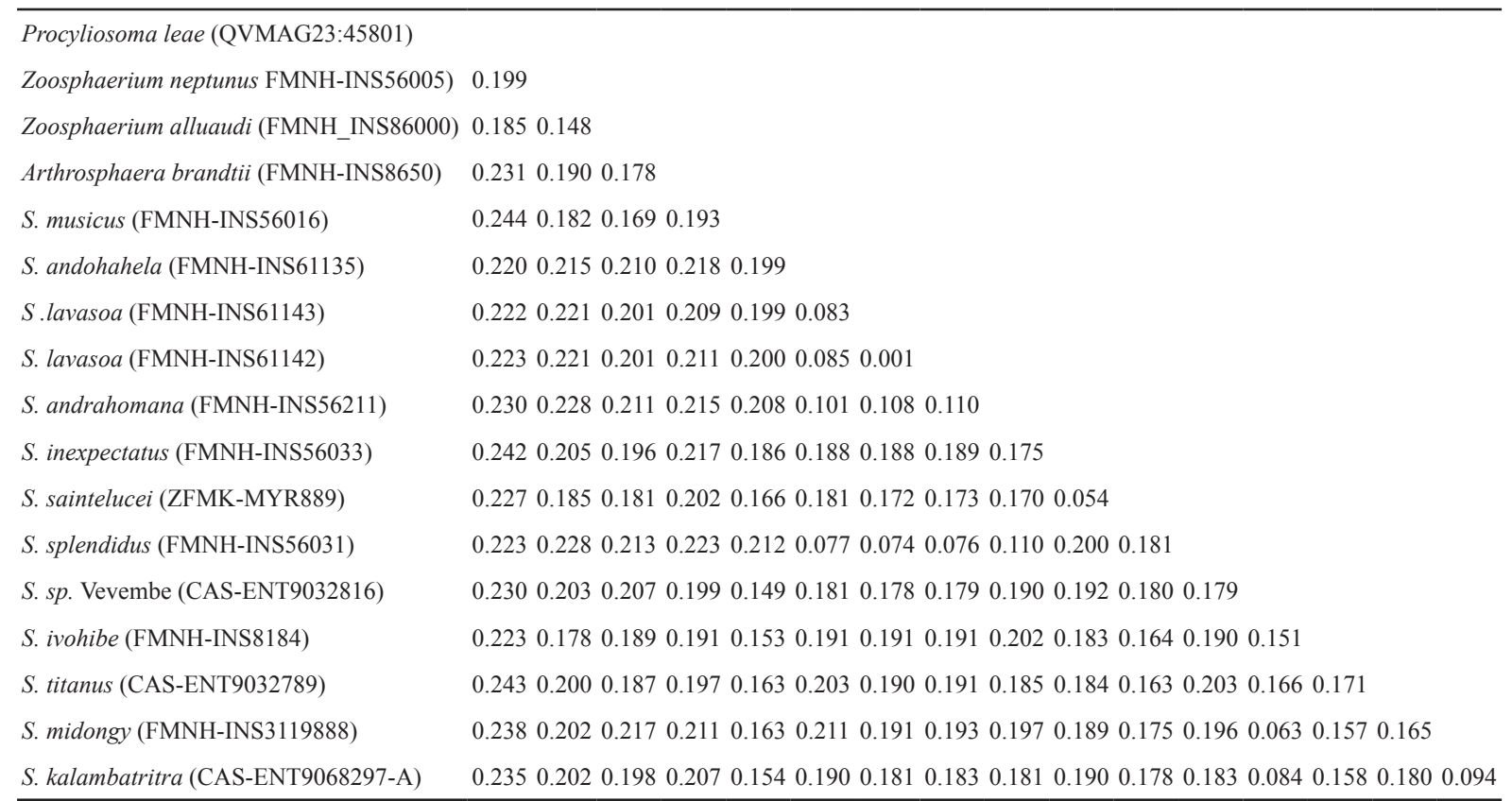

in matrix format (Table 2). The best fitting substitution-model for maximum likelihood analysis was calculated with Modeltest (Tamura \& Nei 1993) as implemented in Mega 6. Codon positions included were $1^{\text {st }}+2^{\text {nd }}+3^{\text {rd }}$. The best fitting model was the General Time Reversal (GTR)-Model (Tavare 1986) with gamma distribution and Invariant sites $(\mathrm{GTR}+\mathrm{G}+\mathrm{I})(\mathrm{lnL}=-4010.400$, Invariant $=0.5302$, Gamma $=$ 1.4196, $\mathrm{R}=3.75520307816161$; Freq A: 0.2640, T: 0.3345, C: 0.2287, G: 0.1726). Phylogenetic analysis was performed in Mega 6 based on the GTR $+\mathrm{G}+\mathrm{I}$ model. A species tree was reconstructed using the maximum likelihood method with gamma-distribution of 5 categories. Initial trees were made automatically using NJ/BioNJ. The bootstrap consensus tree was calculated from 1000 replicates (Felsenstein 1985). The obtained tree was edited in Adobe Illustrator CS2.

\section{Distribution map}

The localities of specimens were mapped in the free software DIVA-GIS v. 7.5.0.0 (Hijmans et al. 2001) on spatial information made freely available by the GADM database v. 1.0 and the Madagascar Vegetation mapping project (Moat \& Smith 2007).

\section{Results}

Order Sphaerotheriida Brandt, 1833

Family Arthrosphaeridae Jeekel, 1974

Genus Sphaeromimus de Saussure \& Zehntner, 1902

For a recent revision, see Wesener et al. (2014).

\section{Key to the species of Sphaeromimus:}

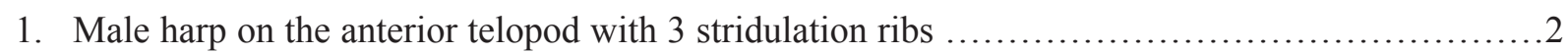

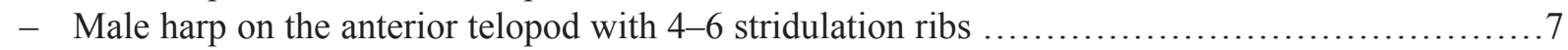


2. Body length $<20 \mathrm{~mm}$. Mid-body legs without a coxal lobe. Endotergum with single row of marginal bristles. Immovable finger of posterior telopod slender, apically strongly curved like a hook. Colour pink or brown

- Body length $>20 \mathrm{~mm}$. Mid-body legs at least with a weak coxal lobe. Endotergum usually with at least two, rarely only one (S. titanus Wesener, 2014) row of marginal bristles. Immovable finger of posterior telopod at least basally wide. Colour black or brown ...........4

3. Colour pink, surface shiny. Process of telopoditomere 2 of anterior telopods in anterior view visible laterally. Littoral forest of Mandena and rainforest of Enato

S. inexpectatus Wesener \& Sierwald, 2005

- Colour light brown, surface dull. Process of telopoditomere 2 of anterior telopods in anterior view not visible. Littoral forest of Sainte Luce, fragment S8

S. saintelucei Wesener, 2014

4. Body length $>30 \mathrm{~mm}$, light brown. Endotergum with single row of marginal bristles. Movable finger of posterior telopod straight (Fig. 2B). Lowland forest of Manombo ......S. titanus Wesener, 2014

- Body length 21-28 mm, black or dark brown. Endotergum with two rows of marginal bristles. Movable finger of posterior telopod curved ................................................. 5

5. Mid-body legs with strongly developed coxal process. Tergite surface shiny. Littoral forest of Sainte Luce, fragment $\mathrm{S} 9$. S. splendidus Wesener \& Sierwald, 2005

- Mid-body legs with barely developed coxal process. Tergite surface dull .6

6. Endotergum with strongly developed cuticular patterns. Movable finger of posterior telopod without small pits, carrying 20-22 crenulated teeth. Andohahela mountain chain, Manantantely, Malio and Isaka-Ivondro .................................... andohahela Wesener, 2014

- Endotergum with weakly developed cuticular patterns. Movable finger of posterior telopod covered with small pits, carrying 23 or 24 crenulated teeth. Inside Grotte d'Andrahomana and in deep ravines $\mathrm{N}$ of Ankapaky

S. andrahomana Wesener, 2014

7. Unique black pattern on orange-reddish basic colour. Harp with 5 ribs. Endotergum with three rows of marginal bristles. Widespread in the SW spiny forest .......S. musicus (Saussure \& Zehntner, 1897)

- Colour different, either uniformly black or brown. Rainforest species ......................... 8

8. Harp with 4 stridulation ribs. Endotergum with two rows of marginal bristles, not reaching tergite margin. Operculum well-rounded. Dark brown to black species. Lavasoa Mountain .........

S. lavasoa Wesener, 2014

- Harp with 5 or 6 stridulation ribs. Endotergum with one to three rows of marginal bristles ...9

9. Harp with 5 stridulation ribs (Fig. 5D). Movable finger of posterior telopod with one or two membranous lobes. Marginal bristles of endotergum protruding beyond tergite margin (Fig. 4B) ...10

- Harp with 6 stridulation ribs (Fig. 9D). Movable finger of posterior telopod with two membranous lobes (Fig. 9G) ....

10. Operculum apically recessed. Medium-sized species. Movable finger of posterior telopod with single membranous lobe and 26 crenulated teeth. Eyes with $>60$ ocelli. Rudimentary lateral palpi consisting of 3 sensilla. Vevembe-Vatovavy area ...S. vatovavy Wesener, 2014

- Operculum well-rounded, typical for genus (Fig. 6A). Gigantic species ( $>50 \mathrm{~mm}$ ). Movable finger of posterior telopod with two membranous lobes and 30 crenulated teeth (Fig. $5 \mathrm{H}$ ). Eyes with $>80$ ocelli. Rudimentary lateral palpi consisting of 4 sensilla (Fig. 3C). Kalambatritra Rainforest 
11. Small, black species, red legs. Endotergum with single sparse row of very short marginal bristles. Posterior telopod with four spines and 36 crenulated teeth. Ivohibe Mountain

S. ivohibe Wesener, 2014

- Gigantic (>50 mm), brown species. Endotergum with two dense rows of long marginal bristles (Fig. 9B). Posterior telopod with two spines and 32 crenulated teeth (Fig. 9H). Midongy Rainforest ...

S. midongy sp. nov.

\author{
Sphaeromimus kalambatritra sp. nov. \\ urn:1sid:zoobank.org:act:620CAD6B-DAB4-4FFC-8556-61357C75AF40
}

Figs 1-6, 11

\title{
Diagnosis
}

Large, massive, brown Sphaeromimus, $>50 \mathrm{~mm}$ long. Differing from all other species of Sphaeromimus in having five stridulation ribs on the male harp (as in S. musicus (Saussure \& Zehntner, 1897) and S. vatovavy Wesener, 2014) in the following characters: tarsus of leg 3 without an apical spine, coxal process almost absent, posterior telopod with two membranous lobes. $>80$ ocelli.

\section{Etymology}

The specific epithet 'kalambatritra', noun in apposition, refers to the type-locality, the Réserve Spéciale de Kalambatritra (Fig. 11).

Material examined $(3 \hat{\partial} \hat{\partial}, 1 \stackrel{+}{)}$

Holotype

MADAGASCAR: $\hat{0}$, Toliaria, Réserve Spéciale Kalambatritra, Befarara, BLF21330, $23^{\circ} 25^{\prime} 04^{\prime \prime}$ S, $46^{\circ} 26^{\prime} 52^{\prime \prime}$ E, alt. $1390 \mathrm{~m}$, montane rainforest, 7 Feb. 2009, B.L. Fisher et al. leg., general collecting (CASENT 9068297-A).

\section{Paratypes}

MADAGASCAR: $1 \hat{\partial}$, same collection data as for holotype (ZFMK MYR06125); $1 \hat{\partial}$, same collection data as for holotype (CASENT 9068297-C); 1 9, Toliaria, Réserve Spéciale Kalambatritra, Ampanihy, BLF21565, 232 $7^{\prime} 49^{\prime \prime} \mathrm{S}, 46^{\circ} 27^{\prime} 47^{\prime \prime} \mathrm{E}$, alt. $1270 \mathrm{~m}$, montane rainforest, 9-10 Feb. 2009, B.L. Fisher et al. leg., general collecting (CASENT 9058301).

\section{Description}

MeAsurements. Male holotype ca $51.5 \mathrm{~mm}$ long, $24.4 \mathrm{~mm}\left(2^{\text {nd }}\right.$ segment $)$ up to $28.2 \mathrm{~mm}\left(10^{\text {th }}\right.$ segment $=$ widest) wide, $14 \mathrm{~mm}\left(2^{\text {nd }}\right.$ segment $)$ high. Female ca $52 \mathrm{~mm}$ long, $24.7 \mathrm{~mm}\left(2^{\text {nd }}\right.$ segment $)$ wide, $15.1 \mathrm{~mm}$ $\left(2^{\text {nd }}\right.$ segment) high (Fig. 1A).

COLORATION OF PRESERVED SPECIMEN (Fig. 1A). Tergites in anterior half dark brown, posterior half light brown, posterior margin with thin dark brown band. Paratergites light brown with dark brown to blackish tips. Paratergite impressions and groove of thoracic shield light brown. Antennae brown, and legs and pleurites light brown to grey. Head laterally around eyes and at posterior margin dark brown, frontally light brown. Collum dark brown. Eyes green.

HEAD. Eyes with $>80$ ocelli, median ocelli small and increasing in size towards lateral and posterior part of eyes (Fig. 1A), several larger ocelli on lateral margin clearly separated from eye. Organ of Tömösváry positioned in antennal-groove (Fig. 1B). Antennae short, protruding to coxa of third leg, not reaching margin of thoracic shield. Antennomere 1 as long as $2+3$; antennomeres $2-5$ of similar length; antennomere 6 as long as 4+5, but shorter than 1. Antennomeres 1-6 and antennal groove densely 
pubescent (Fig. 2A). Antennomere 6 towards disc with single row of sensilla basiconica (Fig. 2B-C). Disc in female with 33/31, in male with 53/55 apical cones, as well as several setae shorter, or as long as, apical cones (Fig. 2B). Margin of labrum with setae.

GNATHOCHILARIUM. Gnathochilarium typical for members of the order Sphaerotheriida, stipes and lamellamentum densely pubescent (Figs 1B, 3A, E). Lateral palpi rudimentary, not distinctly projecting over level of surrounding cuticle, consisting of four sensillae (Fig. 3C). Inner palpi well developed, with field of sensory-cones and scale-like structures (Fig. 3D). Central pads (protuberance of endochilarium) with field of sensory-cones and smaller scale-like structures (Fig. 3E). Endochilarium with deep triangular incision between central pads, central pads projecting lamella-mentum nearly to base of inner palpi.

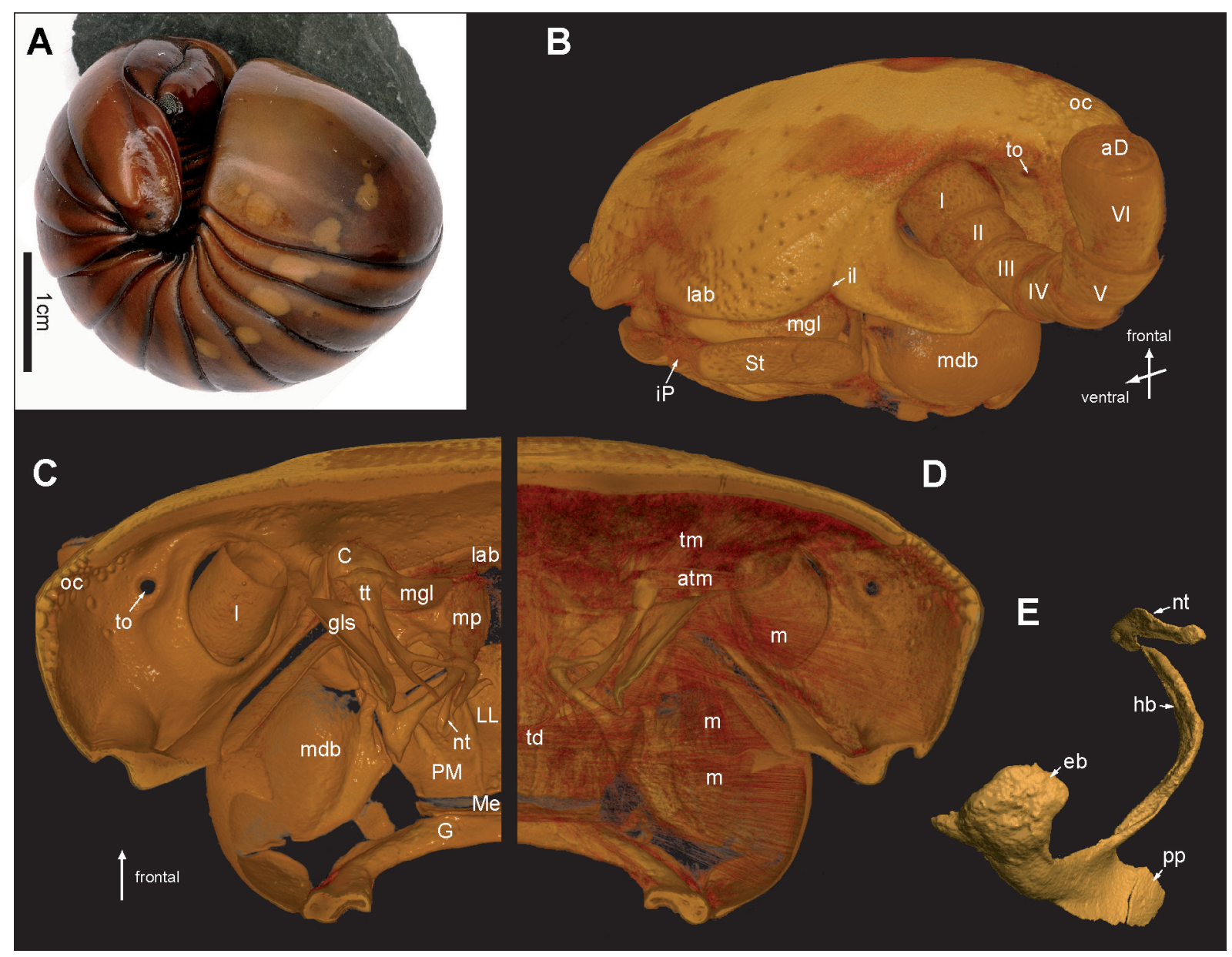

Fig. 1. Sphaeromimus kalambatritra sp. nov. A. Lateral view. B-D. Volume rendering of head based on $\mu$ CT-images, female paratype (CASENT 9058301). B. Head, outer fronto lateral view. C. Head, inner posterior view of sclerotized structures only. D. Head, inner posterior view of sclerotized structures and soft structures. E. Segmentation of the left tentorium and nebententorium, frontal view. Abbreviations: $\mathrm{aD}=$ antennal disc; $\mathrm{atm}=$ antennal muscle; $\mathrm{C}=$ condylus of mandible gnathal lobe; $\mathrm{eb}=$ epipharyngeal bar; $\mathrm{G}=$ gula; gls = gnathal lobe sclerite; $\mathrm{hb}=$ hypopharyngeal bar; il = incisura lateralis; $\mathrm{P}=$ inner palpi; lab = labium; $\mathrm{LL}=$ lamella lingualis; $\mathrm{m}=$ mandibular muscle; $\mathrm{mdb}=$ mandibular base; $\mathrm{Me}=$ mentum; $\mathrm{mgl}=$ mandible gnathal lobe $\mathrm{mp}=$ molar plate; $\mathrm{nt}=$ nebententorium; $\mathrm{oc}=$ ocelli; $\mathrm{PM}=$ paramentum; $\mathrm{pp}=$ posterior process; $\mathrm{St}=$ stipes of gnathochilarium; $\mathrm{td}=$ tendon; $\mathrm{tm}=$ tentorial muscle; to $=$ Tömösváry organ; $\mathrm{tt}=$ tentorium; $\mathrm{I}-\mathrm{VI}=$ antennomeres . 
Lateral endochilarium with densely packed median-pointing setae. Hypopharynx with single row of teeth lateral on both sides, anterior distinctly separated row of 8 teeth (Fig. 3B).

Mandible. Mandible with typical shape of Sphaerotheriida (Fig. 3F), inner tooth 3-combed, with 6 long pectinate lamellae (Fig. 3G), condylus with a single, lower step at its apex (Fig. 3F). Condylus of mandible mounted against cuticular thickening on lateral margin of labrum, anteriorly of antennae (Fig. 1C). Tentorium lacking connection to head capsule via transverse bar. Posterior process triangular and plate-like, laying parallel to plate-like gnathal lobe sclerite. Epipharyngeal bar broad and laminar, running within epipahryngeal wall in direction of mandible condylus, broadening distally. Epipharyngeal bar with short lateral offshoot. Hypopharyngeal bar rod-like, curved within hypopharyngeal wall. Distal tip of hypopharyngeal bar reaches plate-like nebententorium. Nebententorium oriented at right angle to hypopharyngeal bar (Fig. 1E).

Collum. Collum glabrous except for few setae at margins.

THORACIC SHIELD. Thoracic shield glabrous, with a chagrinated (leather-like) surface, few setae in grooves. Grooves deep (Fig. 1A).

BoDy RINGS. Tergites 3-12 with a chagrinated surface, small hair only present at posterior margin and in grooves, paratergite tips of mid-body tergites strongly projecting posteriorly (Fig. 1A). Tergites with single black locking carina.

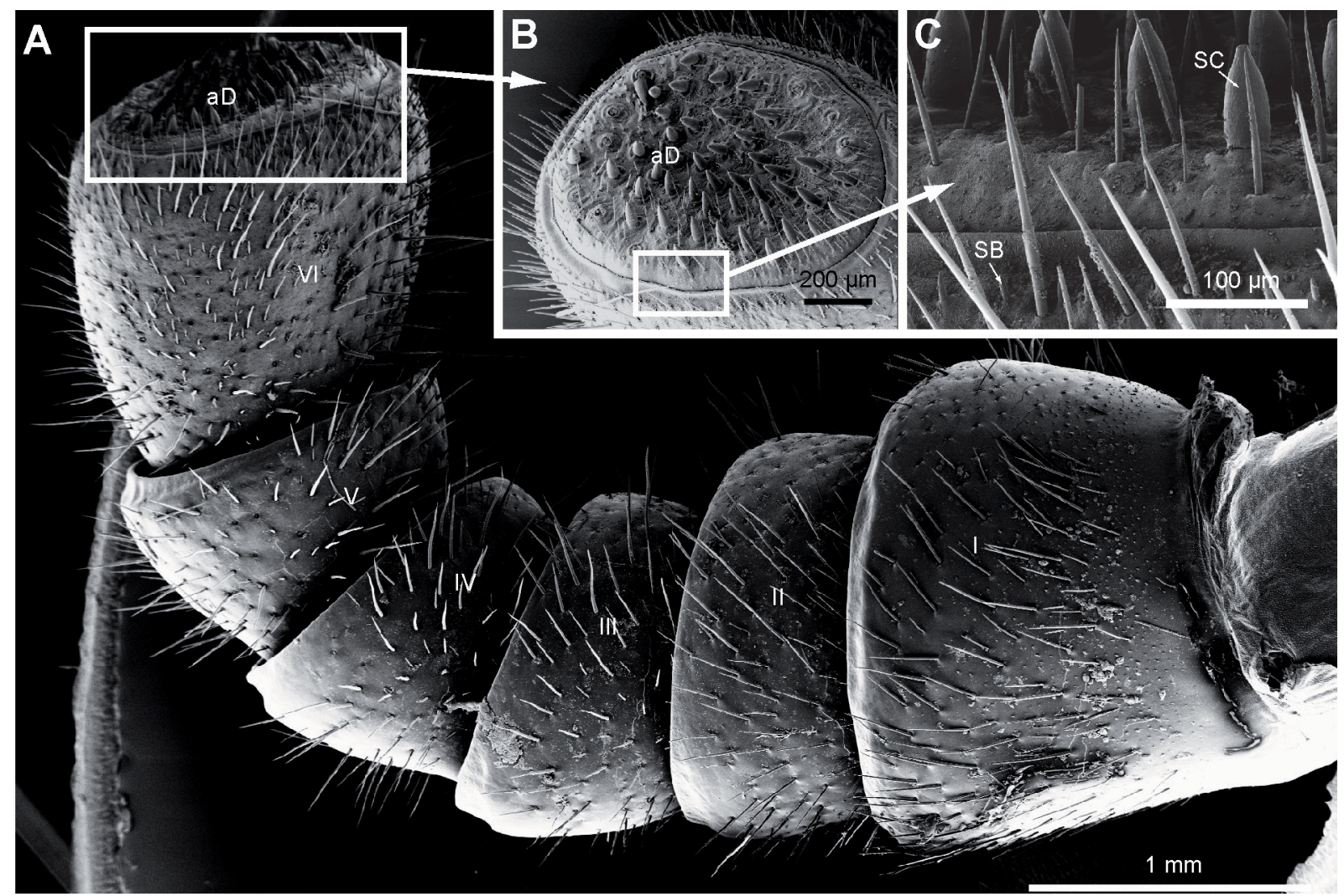

Fig. 2. Sphaeromimus kalambatritra sp. nov., SEM of left antenna, đે, holotype (CASENT 9068297- A). A. Overview. B. Antennal disc, detail. C. Margin of antennal disc, detail. Abbreviations: $\mathrm{aD}=$ antennal disc; $\mathrm{SB}=$ sensilla basiconica; $\mathrm{SC}=$ sensory cone; $\mathrm{I}-\mathrm{VI}=$ antennomeres. 

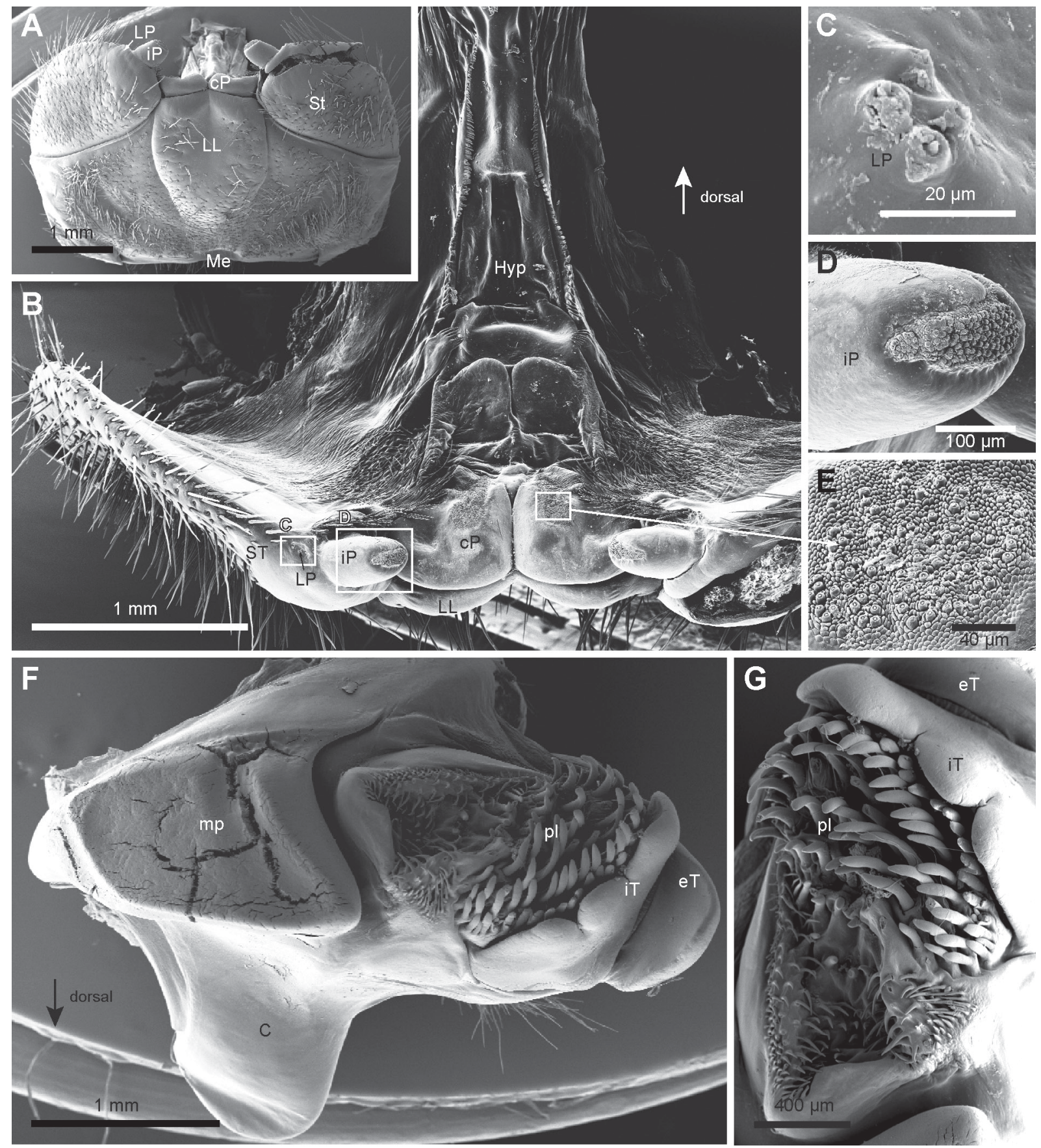

Fig. 3. Sphaeromimus kalambatritra sp. nov., SEM of mouthparts, ð̊, holotype (CASENT 9068297- A). A. Gnathochilarium overview, ventral. B. Gnathochilarium overview, frontodorsal. C. Lateral palpus, detail. D. Inner palpus, detail. E. Central pad, detail. F. Right mandible, overview. G. Pectinate lamellae, detail. Abbreviations: $\mathrm{C}=$ condyles; $\mathrm{cP}=$ central pad; $\mathrm{eT}=$ exterior teeth; Hyp = hypopharynx; $\mathrm{P}=$ inner palpus; $\mathrm{iT}=$ inner teeth; $\mathrm{LL}=$ lamella lingualis; $\mathrm{LP}=$ lateral palpus; $\mathrm{Me}=$ mentum; $\mathrm{mp}=$ molar plate; $\mathrm{pl}=$ pectinate lamellae; $\mathrm{ST}=$ stipes of gnathochilarium. 
ANAL SHIELD. Anal shield large, with a steep edge, entirely glabrous, with lighter and darker patches (Fig. 1A). Underside with single black locking carina, located closer to tergite margins than to pleurite.

ENDOTERGUM. Endotergum inner section with loose field of short, cone-shaped spines and long setae (Fig. 4A). Externally 2-3 dense rows of long marginal bristles, slightly protruding above margin of tergite. Bristles covered with small, triangular spines, apically increasing in density (Fig. 4B).

Stigmatic Plates. First stigma-carrying plate with a well-rounded projecting apex, apex covered with tiny spines and setae (Fig. 5A). Second plate (Fig. 5B) without apex and spines.

FIRST PLEURITE. First pleurite laterally well-rounded, without extensions.

LEGS. Leg 1 with 2, 2 with 4, 3 with 10 ventral spines and no apical spine. Leg pairs 4-21 with 12-16 ventral spines and an apical spine. Small coxa process developed, covered with field of spines (Fig. 5C). Femur 2.0, tarsus 3.3 times as long as wide. All podomeres with few setae (Fig. 5C). Toothed ridge (cleaning comb?) of femur with $>40$ teeth, reaching ca. 0.8 times length of femur. Coxa in anterior aspect basally with a row of teeth, similar to "cleaning comb" on femur. Pronounced coxal process absent.

MALE GONOPORE. Male gonopore typical for genus, plate glabrous, surrounded by relative large membranous area, few small spines basally of gonopore (Fig. 5B).
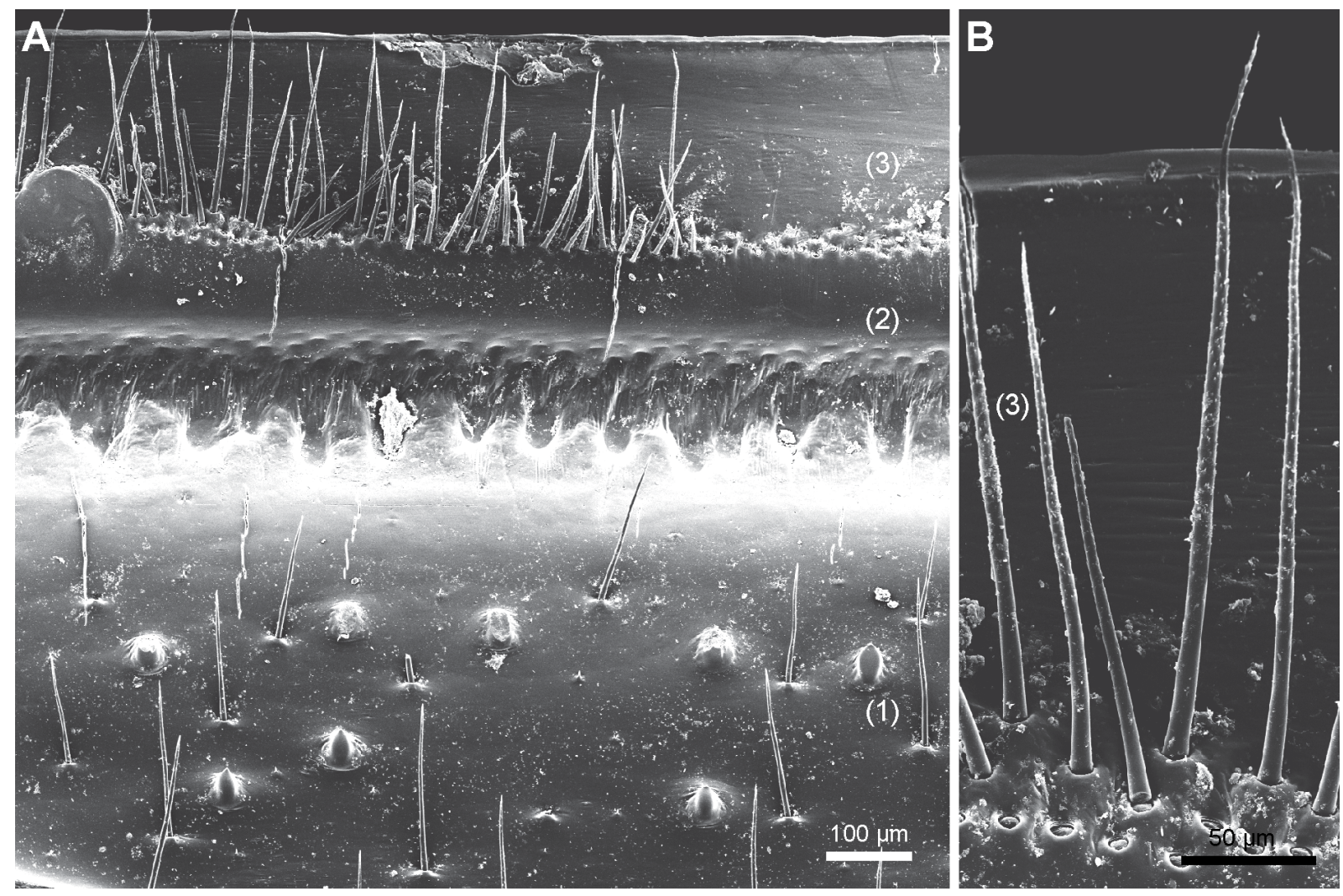

Fig. 4. Sphaeromimus kalambatritra sp. nov., SEM of endotergum, §̂, holotype (CASENT 9068297- A). A. Overview, endotergum. B. Margin of endotergum, detail. Abbreviations: $(1)=$ inner part; $(2)=$ middle part; (3) = outer part. 
ANTERIOR TELOPOD. Harp carrying five well-developed stridulation ribs (Fig. 5D). Shape usual for genus, with setae and tiny teeth at apical margin. Telopoditomere 4 with one large, triangular, apically weakly sclerotized spine and 2 smaller ones (Fig. 5E-F); basally on its anterior side with several tiny teeth. Telopoditomere 3 with triangular hump laterally, located close to border to telopoditomere 4 and juxtaposed to process of telopoditomere 2 (Fig. 5E).

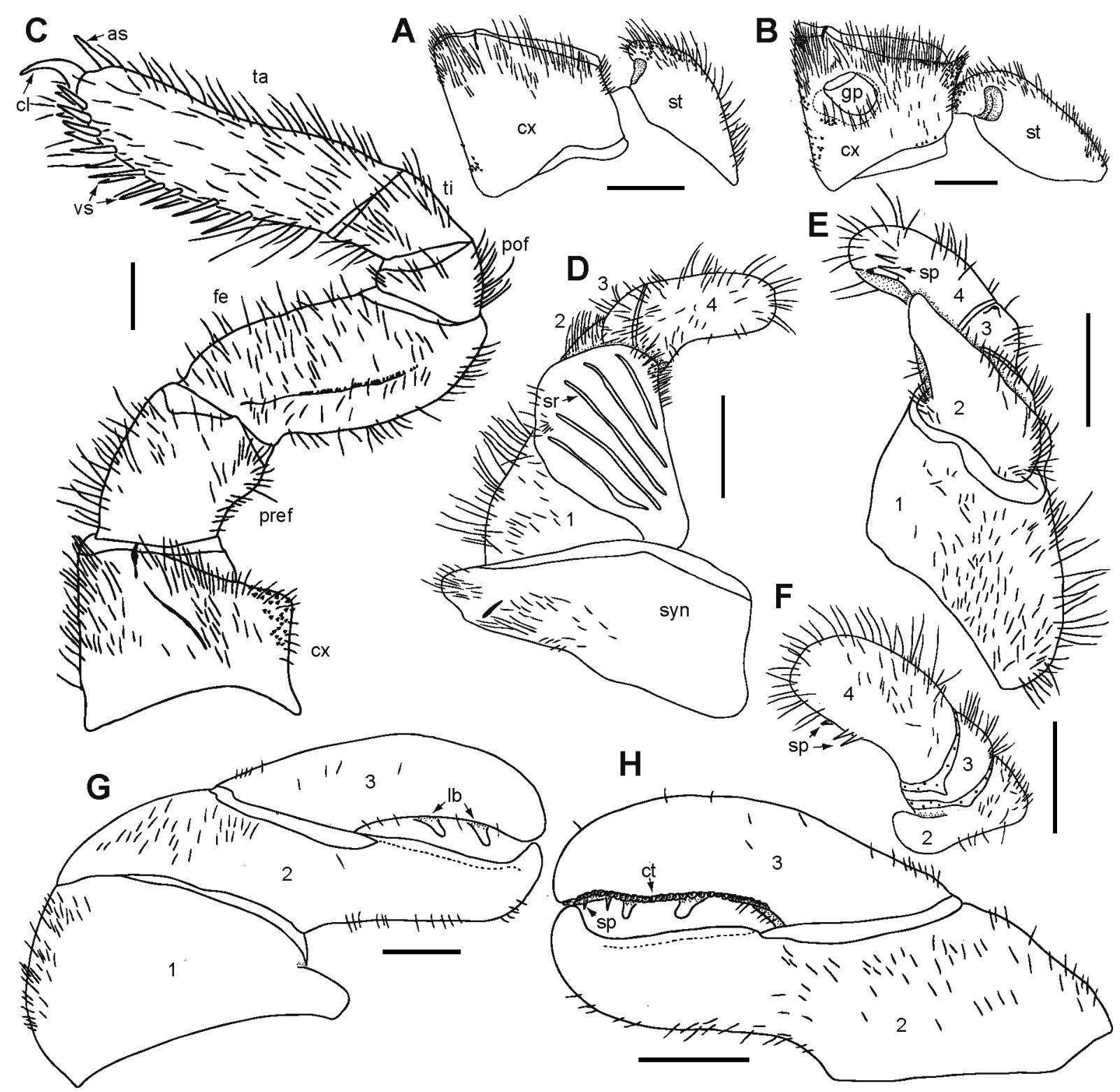

Fig. 5. Sphaeromimus kalambatritra sp. nov., schematic drawing, $\widehat{\jmath}$, holotype (CASENT 9068297-A). A. $1^{\text {st }}$ left coxae and stigma carrying plate. B. $2^{\text {nd }}$ left coxa and stigma carrying plate. C. $9^{\text {th }}$ left leg. D. Left anterior telopod, anterior view. E. Left anterior telopod, posterior view. F. Left anterior telopod, lateral view. G. Left posterior telopod, anterior view. H. Left posterior telopod, posterior view. Abbreviations: as $=$ anterior spine; $\mathrm{cl}=$ claw; $\mathrm{ct}=$ crenulated teeth; $\mathrm{cx}=\mathrm{coxa} ; \mathrm{fe}=$ femur; $\mathrm{gp}=$ gonopore; $\mathrm{lb}=$ lobe; pof $=$ postfemur; pref $=$ prefemur; $\mathrm{sp}=$ spine; $\mathrm{sr}=$ stridulation rib; $\mathrm{st}=$ stigmatic plate $; \mathrm{syn}=$ syncoxite; $\mathrm{ta}=$ tarsus; $\mathrm{ti}=$ tibia; $\mathrm{vs}=$ ventral spine; $1-4=$ podomeres. Scale bars $=1 \mathrm{~mm}$. 

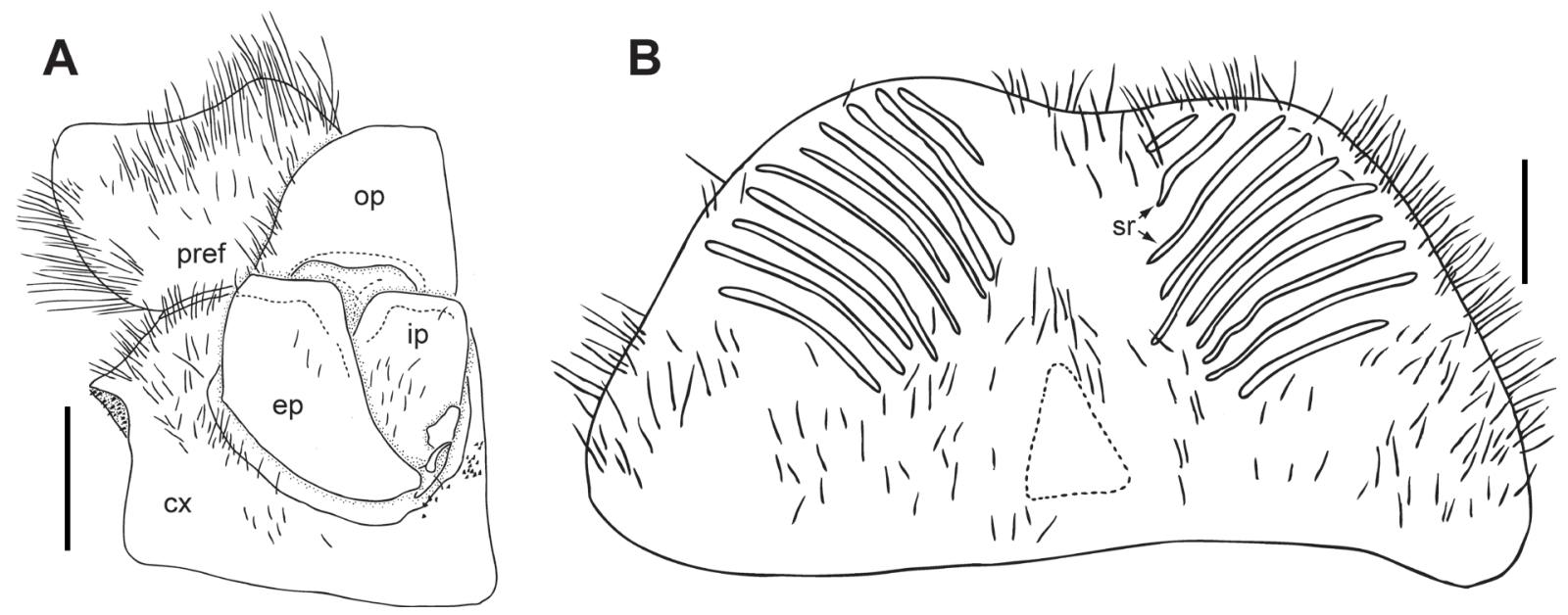

Fig. 6. Sphaeromimus kalambatritra sp. nov., schematic drawing, + , paratype (CASENT 9058301). A. Left vulva $\left(2^{\text {nd }}\right.$ coxa). B. Subanal plate. Abbreviations: $\mathrm{cx}=\mathrm{coxa}$; $\mathrm{ep}=$ exterior plate; ip $=$ interior plate; op $=$ operculum; pref $=$ prefemur; $\mathrm{sr}=$ stridulation ribs. Scale bars $=1 \mathrm{~mm}$.

POSTERIOR TELOPOD. Podomere 3 slightly curved, 3.3 times as long as wide, slightly longer than immovable finger (Fig. 5G-H). Hollowed-out inner margin with two lobes and two spines, posterior aspect with ca 30 small crenulated teeth. Immovable finger straight, basally wide, apically tapering, only apical tip strongly curved towards podomere 3. Podomere 1 with few setae on lateral margin (Fig. 5H), podomere 2 only with few setae at anterior side, posterior side glabrous (Fig. 5G-H). Podomere 3 with only few marginal setae.

Female SeXual CHARActers. Vulva massive. Operculum well-rounded, protruding up to apical third of prefemur, with few marginal setae (Fig. 6A). Subanal plate large, with shallow invagination at apical margin (shape typical for genus). Washboard with ten stridulation ribs on each side, median in anterior half with black triangular field (Fig. 6B). The female carried several hundred eggs with a diameter of $1.5-1.6 \mathrm{~mm}$.

\section{Distribution}

Only known from the type-locality, the Réserve Spéciale de Kalambatritra, which is a mountainous rainforest (Fig. 11). In the same habitat, two undetermined giant pill-millipede species of the genus Zoosphaerium occur sympatrically.

Sphaeromimus midongy sp. nov. urn:lsid:zoobank.org:act:FA9166CE-73E5-41FE-A203-E4C999D2C0EE

Figs 7-9, 11

\section{Diagnosis}

Large, massive, dark brown Sphaeromimus, $>50 \mathrm{~mm}$ long. Differing from the only known species of Sphaeromimus with six stridulation ribs on the male harp (S. ivohibe Wesener, 2014), with which it also shares the two lobes on the movable finger of the posterior telopod, in the following characters: large difference in size and colour pattern, a densely pubescent male gonopore, legs 4-21 with 14 or 15 ventral spines (12 in S. ivohibe), and endotergum with two dense rows of long marginal bristles (single row in S. ivohibe). 


\section{Etymology}

The specific epithet 'midongy', noun in apposition, refers to the type-locality, the Parc National de Midongy.

\section{Material examined $\left(\begin{array}{ll}1 & \nwarrow\end{array}\right)$}

\section{Holotype}

MADAGASCAR: 1 ก, Province de Fianarantsoa, Parc National de Midongy-Befotaka, $11.5 \mathrm{~km}$ SW of Befotaka village, VS-1536, 23⒌ $53.3^{\prime} \mathrm{S}, 46^{\circ} 53.8^{\prime} \mathrm{E}, 1055 \mathrm{~m}$ alt., dense humid transitional lowland and montane forest, 27 Feb. 2008, V. Soarimalaia leg. (FMNH-INS 3119888).

\section{Description}

Measurements. Male holotype ca $51.5 \mathrm{~mm}$ long, $24.1 \mathrm{~mm}$ ( $2^{\text {nd }}$ segment $)$ and $26.1 \mathrm{~mm}$ ( $9^{\text {th }}$ segment $)$ wide, $14.2 \mathrm{~mm}\left(2^{\text {nd }}\right.$ segment $)$ high.

COLORATION OF PRESERVED SPECIMEN. Tergites dark brown with black tips, posterior margin with a light brown band which is bordered anteriorly and posteriorly by thinner black bands. Paratergite impressions and groove of thoracic shield lighter brown. Legs, antennae, pleurites, head and collum brown, eyes green.

HEAD. Eyes with $>80$ ocelli. Antennae short, protruding to third leg pair. Antennomere 1 as long as $2+3$; 2 shorter than $3 ; 3-5$ of similar length; 6 slightly shorter than $4+5$. Antennomeres $1-6$ densely pubescent

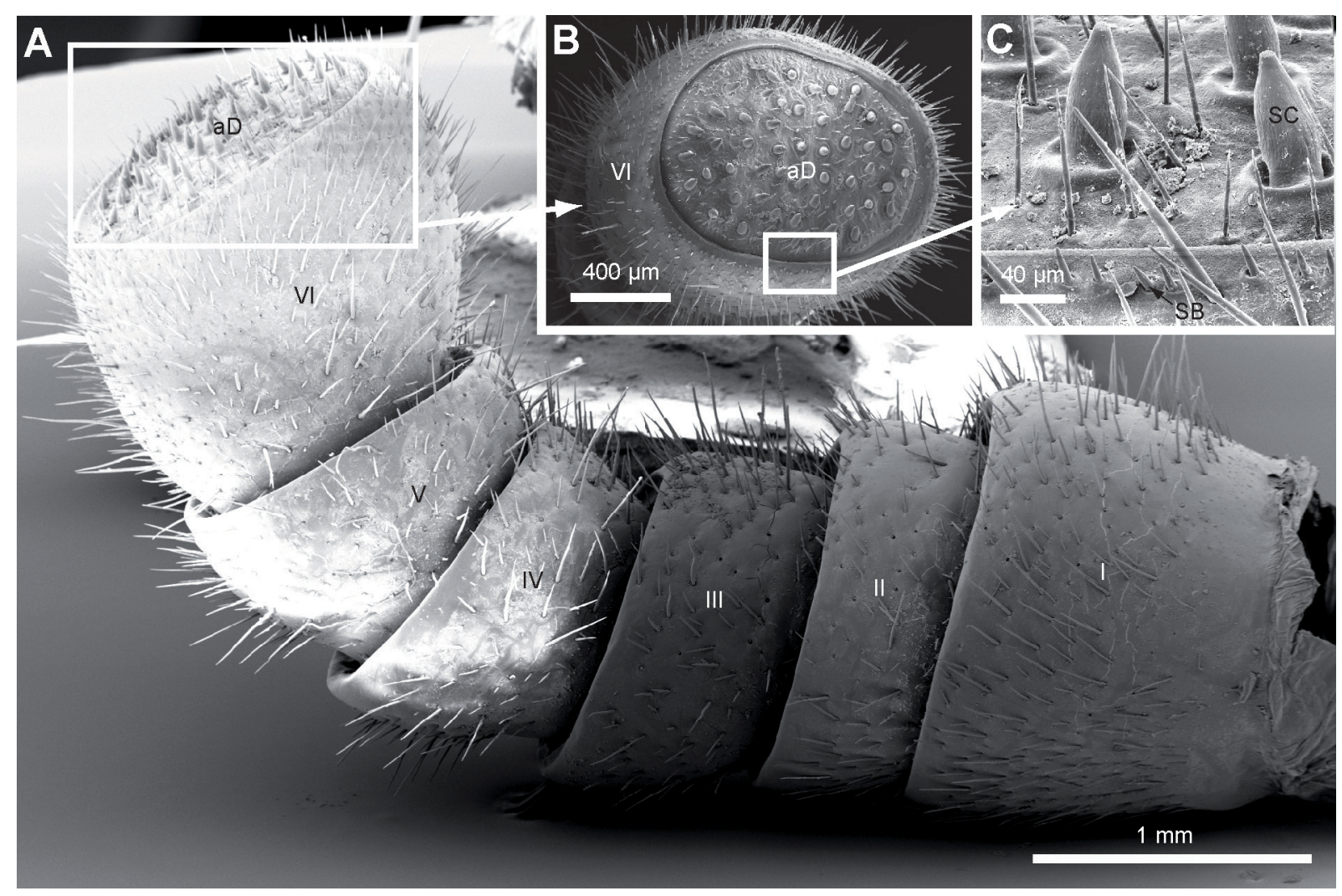

Fig. 7. Sphaeromimus midongy sp. nov., SEM of left antenna, Ô, holotype (FMNH-INS 3119888). A. Overview. B. Detail of antennal disc. C. Detail of margin of antennal disc. Abbreviations: $\mathrm{aD}=$ antennal disc; $\mathrm{SB}=$ sensilla basiconica; $\mathrm{SC}=$ sensory cone; $\mathrm{I}-\mathrm{VI}=$ antennomeres. 
(Fig. 7A). Antennomere 6 towards disc with single row of sensilla basiconica (Figs 7B, C). Disc of male with 50/49 apical cones as well as several sensillae shorter or as long as sensory cones (Fig. 7B). Organ of Tömösváry in antennal groove close to eye. Margin of labrum with setae.

MOUTHParTs. Not dissected.

Collum. Collum glabrous except for few setae at margins.

THoRACIC SHIELD. Thoracic shield chagrinated (leather-like). Grooves deep, covered with setae.

BoDY RINGS. Paratergites 3-12 with posterior margin smooth, rest chagrinated, with hairs on posterior and anterior margin, paratergite tips of mid-body tergites strongly projecting posteriorly.

ANAL SHIELD. Anal shield massive, well-rounded, lacking pubescent area. Underside with single black locking carina, located closer to tergite margins than to pleurite.

Endotergum. Endotergum inner section with setae and triangular spines (Fig. 8A). Between margin and inner area with single row of large, elliptical cuticular patterns. Externally two row of marginal bristles. Bristles protruding weakly above tergite margin. Bristles with small triangular spines, apically increasing in density (Fig. 8B).

Stigmatic Plates. First stigma-carrying plate with a well-rounded, projecting apex covered by hairs (Fig. 9A). Second plate without apex, but with field of teeth opposite of coxa (Fig. 9B).

FIRST PLEURITE. First pleurite laterally well-rounded, without extensions.

LEGs. Leg 1 with 4, 2 with 5 ventral spines and no apical spine; leg 3 with 10 ventral spines and a short apical spine. Leg pairs 4-21 with 14 or 15 ventral spines. Coxa process weakly developed, with small, black, triangular spines (Fig. 9C). Femur 1.5, tarsus 3.5 times as long as wide. All podomeres
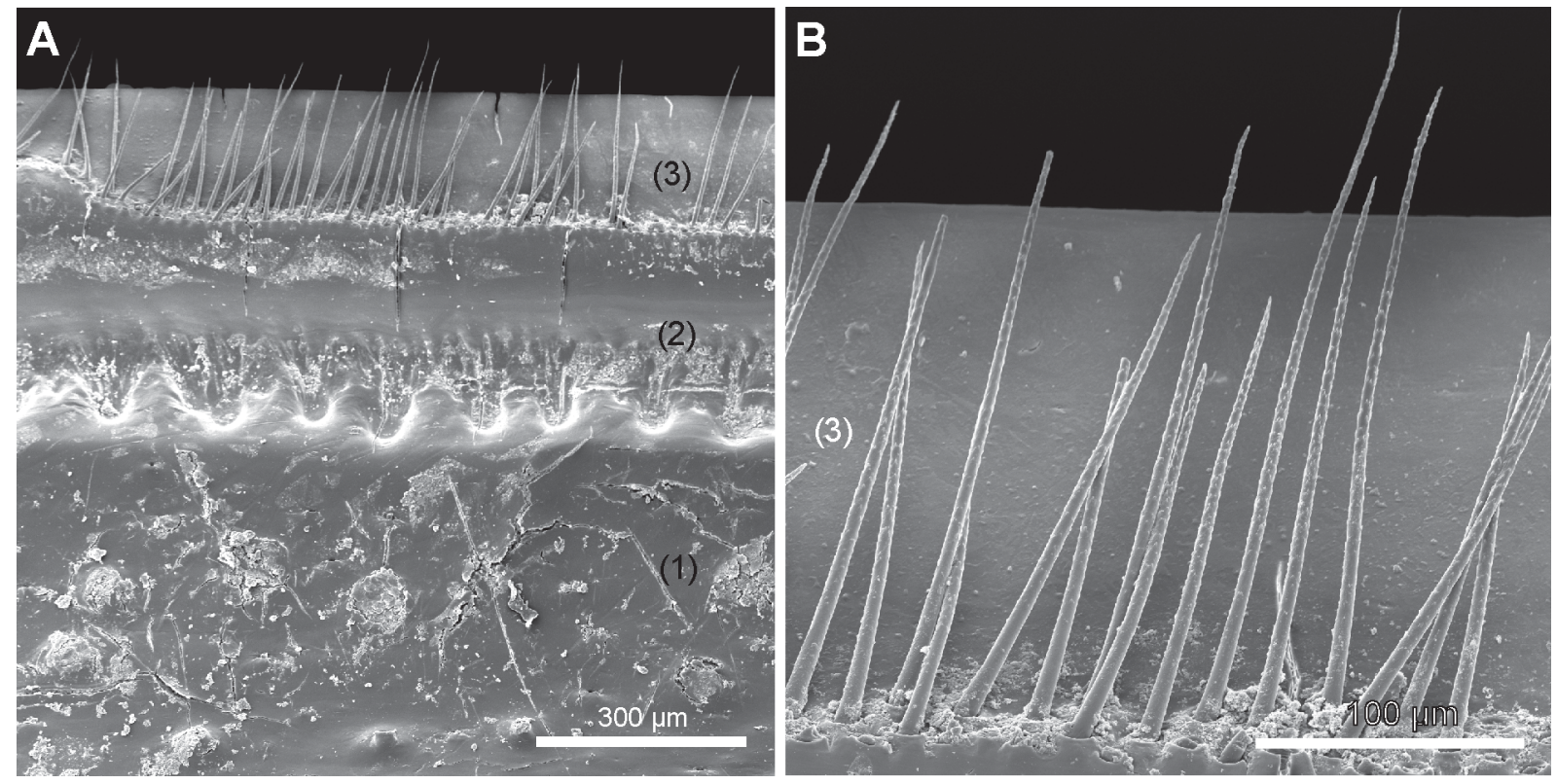

Fig. 8. Sphaeromimus midongy sp. nov., SEM of endotergum, Ő, holotype (FMNH-INS 3119888). A. Overview, endotergum. B. Margin of endotergum, detail. Abbreviations: (1) = inner part; (2) = middle part; (3) = outer part. 
densely pubescent (Fig. 9C). Toothed ridge of femur ca $2 / 3$ length of femur, with 40 small teeth, distally increasing in size. Coxa in anterior aspect basally with a row of teeth, similar to toothed ridge on femur.

MALE GONOPORE. Male gonopore densely pubescent, shape typical for genus (Fig. 9B).

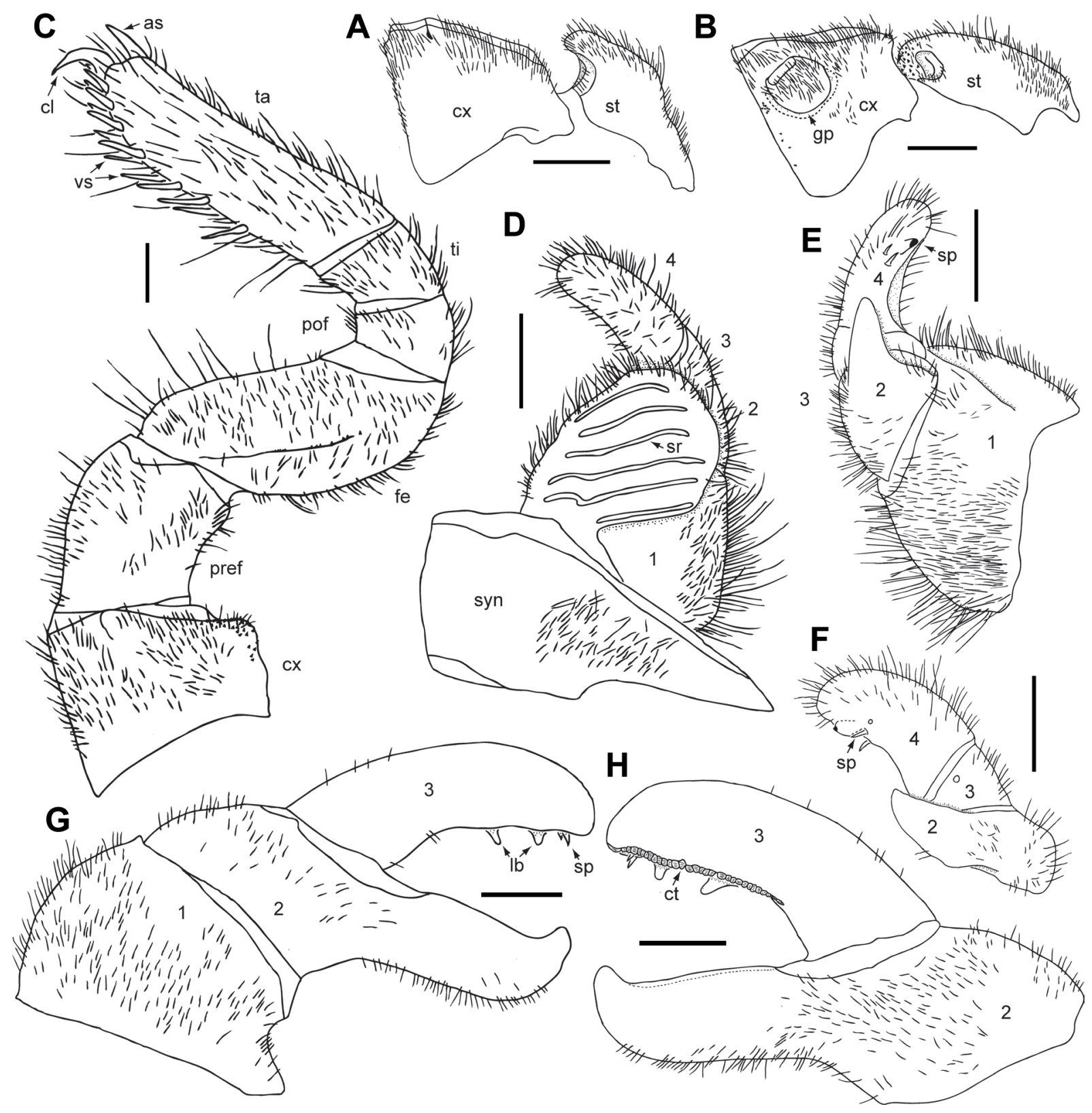

Fig. 9. Sphaeromimus midongy sp. nov., schematic drawing, $\widehat{o}$, holotype (FMNH-INS 3119888). A. $1^{\text {st }}$ left coxae and stima carrying plate. B. $2^{\text {nd }}$ left coxae and stigma carrying plate. C. $9^{\text {th }}$ left leg. D. Anterior view of right anterior telopod. E. Posterior view of right anterior telopod. F. Lateral view of right anterior telopod. G. Left posterior telopod, anterior view. H. Posterior view of left posterior telopod. Abbreviations: as = anterior spine; $\mathrm{cl}=\mathrm{claw} ; \mathrm{ct}=$ crenulated teeth; $\mathrm{cx}=\mathrm{coxa} ; \mathrm{fe}=$ femur; $\mathrm{gp}=$ gonopore; $\mathrm{lb}=$ lobe; pof = postfemur; pref = prefemur; $\mathrm{sp}=$ spine; $\mathrm{sr}=$ stridulation $\mathrm{rib} ; \mathrm{st}=$ stigmatic plate; $\mathrm{syn}=$ syncoxite; $\mathrm{ta}=$ tarsus; $\mathrm{ti}=$ tibia; vs $=$ ventral spine; $1-4=$ podomeres. Scale bars $=1 \mathrm{~mm}$. 
Anterior telopod. Harp with six stridulation ribs (Fig. 9D), all ribs of similar length. Shape usual for genus, telopoditomere 4 with one large triangular spine with sclerotized tip and 2 smaller spines (Figs 9E-F). Telopoditomeres 3 and 4 with sclerotized spots.

POSTERIOR TELOPOD. Podomere 3 slightly curved, 3 times longer than wide, slightly longer than immovable finger (Fig. 9G). Hollowed-out inner margin with two lobes and two spines, posterior aspect with ca 32 small crenulated teeth (Fig. 9H). Immovable finger constant in width, only apically tapering, tip weakly curved towards podomere 3 . Podomere 1 with setae, podomere 2 with few setae on anterior and posterior side. Podomere 3 and immovable finger with only few marginal setae (Fig. 9G-H).

\section{Female sexual characters}

Unknown.

\section{Distribution}

Only known from the type-locality, the Parc National de Midongy (Fig. 11). Mountainous rainforest.

\section{Barcoding results}

S. kalambatritra sp. nov. shows the lowest genetic distance to the undetermined specimen from Vevembe (Fig. 11), with a $8.4 \%$ divergence. The distance of $S$. kalambatritra sp. nov. to $S$. midongy sp. nov. from the only rainforest located close-by is $9.4 \%$. The highest distance of $S$. kalambatritra sp. nov. within Sphaeromimus is $19 \%$ to both S. inexpectatus and S. andohahela (Table 2). S. midongy sp. nov. also has the lowest pairwise distance to the undetermined Vevembe specimen, with $6.3 \%$, and the highest to S. andohahela with $21.1 \%$ (Table 1).

The maximum likelihood tree receives high support for nodes at the species level (e.g., $100 \%$ for S. musicus) and shallower nodes (e.g., $100 \%$ for S. saintelucei + S. inexpectatus), while deeper nodes receive no support (e.g., $39 \%$ for $S$. titanus $+(S$. kalambatritra sp. nov. $+(S$. midongy sp. nov. + Specimen from Vevembe $))+($ S. ivohibe $+S$. musicus $)$ ). Branches separating taxa are relatively long (Fig. 10). Sphaeromimus is recovered as a monophyletic group with $74 \%$ bootstrap support. A sistergroup relationship of $S$. midongy with the undetermined specimen from Vevembe receives high support (99\%) (Fig. 10). S. kalambatritra sp. nov. as the sister-group to S. midongy sp. nov. + the undetermined specimen from Vevembe receives $100 \%$ bootstrap support. This clade is separated by a long branch from a group comprising S. ivohibe and S. musicus. Monophyly of those four taxa is supported with $63 \%$ bootstrap support (Fig. 10).

\section{Discussion}

\section{Updated distribution of Sphaeromimus}

Including the two newly described species, the genus Sphaeromimus is still restricted to southeastern Madagascar. With S. kalambatritra sp. nov., we record the western-most distribution of a rainforest species (Fig. 11). S. kalambatritra sp. nov. was, as all other species of Sphaeromimus, found to live in direct sympatry with at least one species of Zoosphaerium.

\section{Micro-CT in taxonomy and phylogeny}

Already Akkari et al. (2015) showed the great potential of micro-CT in millipede taxonomy. It can be used to visualize and infer internal morphological characters, which can be exploited not only for the species description itself, but also for subsequent morphological phylogenetic reconstruction as demonstrated by Blanke \& Wesener (2014). Here, we show that micro-CT is not only a useful tool to examine hard sclerotized structures like the head capsule, the gnathal lobe sclerite and the tentorium (Fig. 1C), but also to visualize soft parts like the collagenous tendon and single muscles (Fig. 1D). 


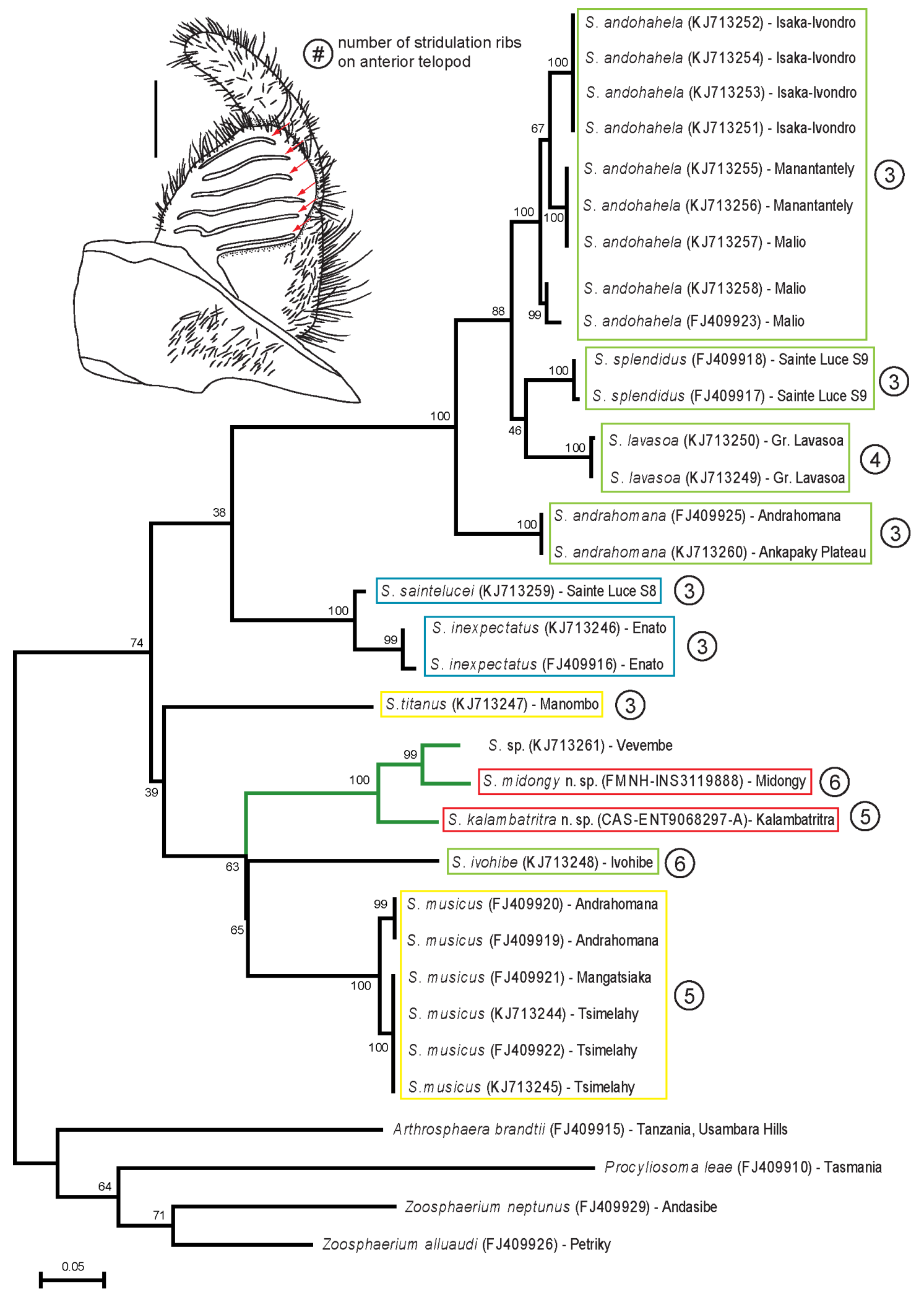

Fig. 10. Maximum likelihood tree based on the COI sequence after 1000 bootstrap replicates under the GTR $+\mathrm{G}+\mathrm{I}$ model. Branch length indicates genetic distance. Numbers on branches indicate bootstrap support. Schematic drawing shows right anterior telopod of Sphaeromimus midongy sp. nov. Numbers in circles indicate number of stridulation ribs on the male harp. 
The advantage of micro-CT compared to conventional invasive methods is that it does not damage the specimen. This is especially important, because many new species are found in museum collections and are only represented by a few or a single specimen, like the species described in this study. These specimens cannot be examined without permission and should not be damaged. This makes it nearly impossible to study internal features by dissection or histological sectioning. Furthermore, it makes it possible to share morphological information via public databases, which otherwise opens up a variety of new possibilities, as outlined by Akkari et al. (2015). Therefore, we suggest considering the use of micro-CT in taxonomic studies if it seems advantageous to include internal characters. For the first time we add internal characters to the taxonomic description of a member of the order Sphaerotheriida. We describe the structure of the tentorium and the articulation of the mandible condylus. At this point, it is not possible to state which of these characters show inter- or intraspecific variations, because there is no data available yet for other species, except the descriptions of the tentorium of Arthrosphaera dentigera (Verhoeff 1930) by Verhoeff (1932) and Sphaeropoeus modiglianii Silvestri, 1895, a Zephroniidae, by Silvestri (1903). Future studies will elaborate whether any useful taxonomic characters can be collected from these inner morphological features. The structure of the tentorium of S. kalambatritra sp. nov. corresponds to the state described for A. dentigera. The hypopharnygeal bar of the tentorium of Sphaeromimus is elongated, while the nebententorium is more stout compared to the state depicted by Silvestri (1903) for the Zephroniidae. Furthermore, the posterior process of Sphaeromimus seems larger than in Sphaeropoeus, although this could be due to the perspective Silvestri chose to depict the tentorium. The shape of the epipharyngeal bar shows a high similarity in both.

\section{Genetic analysis}

The high genetic distances between the species of Sphaeromimus suggest an early speciation event, as previously suggested by Wesener et al. (2010, 2014). The COI gene probably lost its resolution due to the accumulation of reverse substitutions over time. Klopfstein et al. (2010) and Townsend \& Leuenberger (2011) showed that the 'informativeness' of the COI gene declines in older splits.

As shown in several studies on giant pill-millipedes (e.g., Wesener et al. 2010 for Sphaeromimus; Wongthamwanich et al. 2012 and Golovatch et al. 2012 for Zephroniidae), the COI gene remains nevertheless a powerful tool for the taxonomy and identification of giant pill-millipede species. It makes it possible to assign specimens of different stages, gender or with high morphological intraspecific variation to a species. Otherwise, it is not necessarily possible to assign such specimens to a species based solely on morphological evidence (see Wesener et al. 2014). The COI barcode shows a close and well-supported relationship between $S$. midongy sp. nov. and the undetermined (female) specimen from Vevembe (Fig. 11). In previous studies, the specimen from Vevembe was separated from S. ivohibe + S. musicus by a long branch and with weak support (see Wesener et al. 2014). With a genetic distance of $6.3 \%$ between $S$. midongy sp. nov. and the specimen from Vevembe, they cannot be assigned to the same species based on COI data alone until morphological characters of the male of the Vevembe population become available. Thus, $S$. inexpectatus and $S$. saintelucei show a genetic distance of only $4.1 \%$ in our analysis and $4.0 \%$ in the study conducted by Wesener et al. (2014), and are regarded as separate species based on morphological characters. Nevertheless, the genetic distance of the COI sequence fragment in Sphaeromimus is usually 8-20\% between two species (Wesener et al. 2014). Therefore, it cannot be ruled out that the specimen from Vevembe belongs to $S$. midongy sp. nov. To draw sufficiently supported conclusions, further studies and sampling of these areas are needed. A comparison of the genetic distance and the geographical distance reveal an interesting biogeographic pattern. S. ivohibe and the specimen from Vevembe, which are separated by ca $43 \mathrm{~km}$ (Fig. 11), show a genetic distance of $15.1 \%$ while S. midongy sp. nov. and the specimen from Vevembe are separated by $125 \mathrm{~km}$ (Fig. 11), and have a genetic distance of $6.3 \%$. The genetic distance between S. midongy sp. nov. and S. kalambatritra sp. nov. 
is $9.4 \%$, although the geographical distance is only $65 \mathrm{~km}$ (Fig. 11). This demonstrates that species endemic to geographically close habitats are not necessarily closely related (see also Wesener et al. 2014).

\section{Number of stridulation ribs of the male harp}

Comparing the number of stridulation ribs on the male harp to the species-tree, there seems to be one clade with an increased number of stridulation ribs (Fig. 10). While most known Sphaeromimus have three stridulation ribs (4 in $S$. lavasoa) the clade (S. kalambatritra sp. nov. $+(S$. midongy sp. nov. + specimen from Vevembe $))+($ S. musicus + S. ivohibe $)$ has five or six stridulation ribs. However, it has

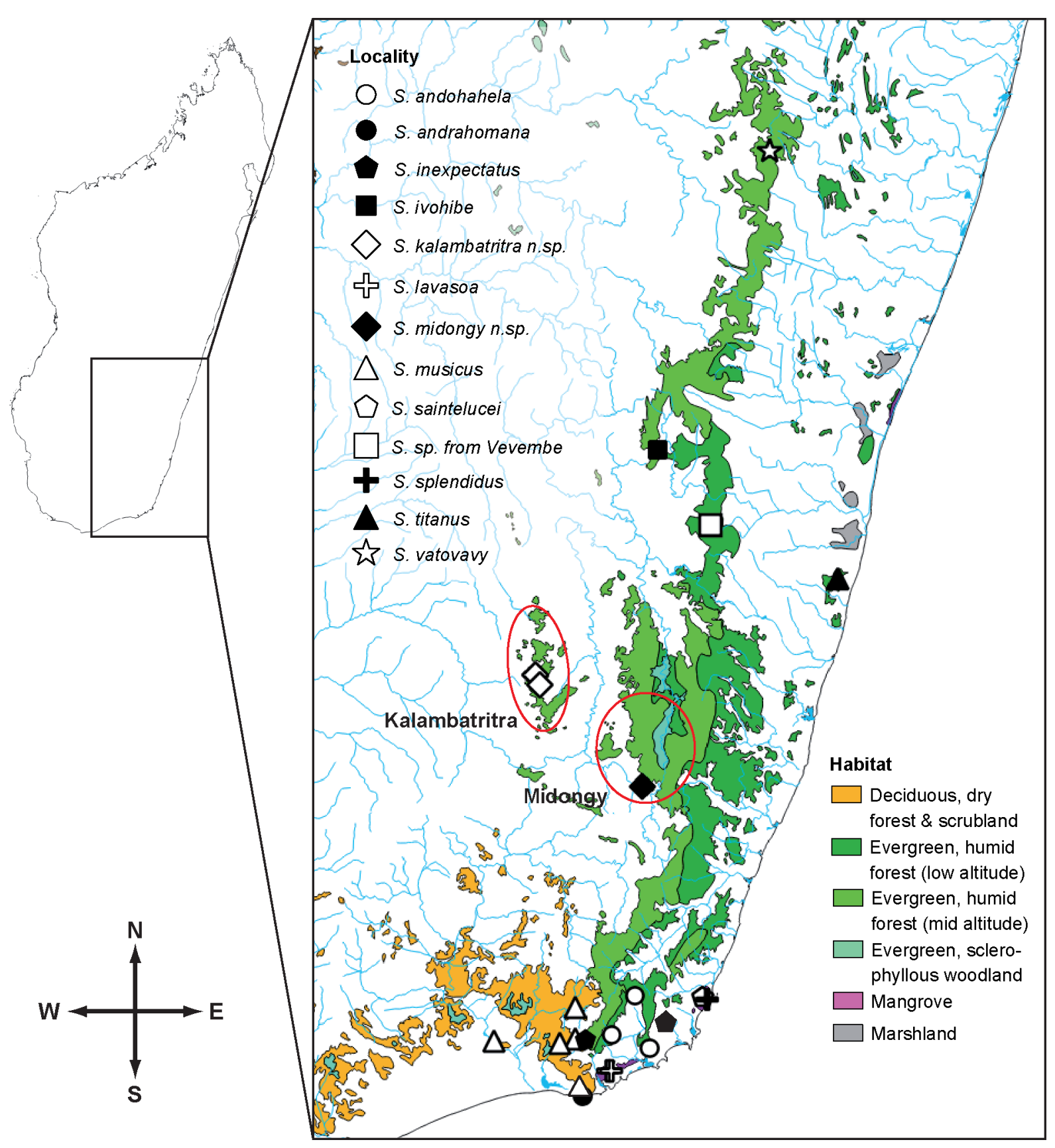

Fig. 11. Distribution of the genus Sphaeromimus de Saussure \& Zehntner, 1902 in south-eastern Madagascar. Map modified after Moat \& Smith 2007. 
to be noted that there is no information on the number in the specimen from Vevembe, since we know a single female only. We can assume that the ancestral state is a low number of stridulation ribs on the male harp, as seen in other representatives of the family Arthrosphaeridae. In Arthrosphaera the number of stridulation ribs can vary between none and 2 ribs, Microsphaerotherium has one rib and Zoosphaerium has one or two (Wesener \& VandenSpiegel 2009). The advantage of a high number of stridulation ribs remains unclear. Thus, the habitats of species with high or low numbers of stridulation ribs overlap. Species of Sphaeromimus and Zoosphaerium usually occur in sympatry (Wesener et al. 2014). The number of ribs might have an impact on the sound production, but only for South African species information about the produced sounds is available (Wesener et al. 2011).

\section{Acknowledgements}

This work is the result of a study class conducted in the course of the international Master OEP program based at the University of Bonn. The examined material was kindly provided by Petra Sierwald, Crystal Maier (both FMNH) and Darrel Ubick (CAS). We especially thank the collectors Brian L. Fisher (CAS) and Steve M. Goodman (FMNH), as well as V. Soarimalaia, for their continuous inventorying efforts on Madagascar, unearthing numerous undescribed species. Claudia Etzbauer (ZFMK) is thanked for assistance in the molecular laboratory. Karen Ulmen and Hans-Joachim Krammer (both ZFMK) provided help at the SEM. Claudia Koch and Peter Rühr (ZFMK) are thanked for assistance at the micro-CT. Thorsten Klug made habitus pictures. Christina Sagorny is thanked for advice and help during the whole project. Brian L. Fisher, Mitch Irwin (Northern Illinois University) and Jörg Ganzhorn (University of Hamburg) kindly provided information about the sampling sites. Futhermore, we thank the two anonymous reviewers and the editor Rudy C.A.M. Jocqué for their comments and suggestions.

\section{References}

Akkari N., Enghoff H. \& Metscher B.D. 2015. A new dimension in documenting new species: highdetail imaging for myriapod taxonomy and first 3D cybertype of a new millipede species (Diplopoda, Julida, Julidae). PloS One 10 (8): e0135243. https://doi.org/10.1371/journal.pone.0135243

Altschul S.F., Gish W., Miller W., Myers E.W. \& Lipman D.J. 1990. Basic local alignment search tool. Journal of Molecular Biology 215 (3): 403-410. https://doi.org/10.1016/S0022-2836(05)80360-2

Astrin J.J. \& Stüben P.E. 2008. Phylogeny in cryptic weevils: molecules, morphology and new genera of western Palaearctic Cryptorhynchinae (Coleoptera: Curculionidae). Invertebrate Systematics 22 (5): 503-522. https://doi.org/10.1071/IS07057

Blanke A. \& Wesener T. 2014. Revival of forgotten characters and modern imaging techniques help to produce a robust phylogeny of the Diplopoda (Arthropoda, Myriapoda). Arthropod Structure \& Development 43: 63-75. https://doi.org/10.1016/j.asd.2013.10.003

Bora P., Randriambahiniarime M.O., Rabemananjara F.C.E., Ramilijaona O.R., Glaw F. \& Vences M. 2007. A rapid assessment survey of the herpetofauna at Befotaka-Midongy National Park, south-eastern Madagascar. Zoosystematics and Evolution 83 (2): 170-178. https://doi.org/10.1002/mmnz.200700007

Cárcamo H.A., Abe T.A., Prescott C.E., Holl F.B. \& Chanway C.P. 2000. Influence of millipedes on litter decomposition, $\mathrm{N}$ mineralization, and microbial communities in a coastal forest in British Columbia, Canada. Canadian Journal of Forest Research 30 (5): 817-826. https://doi.org/10.1139/x00-014

Dewar R.E. \& Wright H.T. 1993. The culture history of Madagascar. Journal of World Prehistory 7 (4): 417-466. https://doi.org/10.1007/BF00997802

Enghoff H. 2003. Diplopoda, millipedes. In: Goodman S.M. \& Benstead J.P. (eds) Natural History of Madagascar: 617-627. University of Chicago Press, Chicago. 
Felsenstein J. 1985. Confidence limits on phylogenies: an approach using the bootstrap. Evolution 39 (4): 783-791. https://doi.org/10.2307/2408678

Ganzhorn J.U., Lowry P.P., Schatz G.E. \& Sommer S. 2001. The biodiversity of Madagascar: one of the world's hottest hotspots on its way out. Oryx 35 (4): 346-348.

https://doi.org/10.1046/j.1365-3008.2001.00201.x

Glaw F. \& Verdes M. 2003. Introduction to amphibians. In: Goodman S.M. \& Benstead J.P. (eds) Natural History of Madagascar: 883-898. University of Chicago Press, Chicago.

Golovatch S.I., Wesener T., Mauriès J.P. \& Semenyuk I.I. 2012. On the identities of Cryxus Leach, 1814 and Zephronia Gray, 1832, the oldest generic names in the millipede order Sphaerotheriida (Diplopoda). Arthropoda Selecta 21 (4): 273-294.

Goodman S.M., Ganzhorn J.U. \& Rakotondravony D. 2003. Introduction to mammals. In: Goodman S.M. \& Benstead J.P. (eds) Natural History of Madagascar: 1159-1186. University of Chicago Press, Chicago.

Green G.M. \& Sussman R.W. 1990. Deforestation history of the eastern rain forests of Madagascar from satellite images. Science 248 (4952): 212-215. https://doi.org/10.1126/science.248.4952.212

Hall T.A. 1999. BioEdit: a user-friendly biological sequence alignment editor and analysis program for Windows 95/98/NT. Nucleic Acids Sympsoium 41: 95-98.

Harper G.J., Steininger M.K., Tucker C.J., Juhn D. \& Hawkins F. 2007. Fifty years of deforestation and forest fragmentation in Madagascar. Environmental Conservation 34 (4): 325-333. https://doi.org/10.1017/S0376892907004262

Hebert P.D. \& Gregory T.R. 2005. The promise of DNA barcoding for taxonomy. Systematic Biology 54 (5): 852-859. https://doi.org/10.1080/10635150500354886

Hebert P.D., Cywinska A. \& Ball S.L. 2003. Biological identifications through DNA barcodes. Proceedings of the Royal Society of London B: Biological Sciences 270 (1512): 313-321. https://doi.org/10.1098/rspb.2002.2218

Hijmans R.J., Guarino L., Cruz M. \& Rojas E. 2001. Computer tools for spatial analysis of plant genetic resources data: 1. DIVA-GIS. Plant Genetic Resources Newsletter 127: 15-19.

Horning N.R. 2012. Debunking three myths about Madagascar's deforestation. Madagascar Conservation and Development 7 (3): 116-119. https://doi.org/10.4314/mcd.v7i3.3

Irwin M.T., Samonds K.E. \& Raharison J.L. 2001. A biological inventory of the lemur community of Réserve Spéciale de Kalambatritra, South-Central Madagascar. Lemur News 6: 24-28.

Jeekel C.A.W. 1999. A new pill-millipede from Madagascar, with a catalogue of the species hitherto described from the island (Diplopoda, Sphaerotheriida). Myriapod Memoranda 1: 5-20

Klopfstein S., Kropf C. \& Quicke D.L.J. 2010. An evaluation of phylogenetic informativeness profiles and the molecular phylogeny of Diplazontinae (Hymenoptera, Ichneumonidae). Systematic Biology 59 (2): 226-241. https://doi.org/10.1093/sysbio/syp105

Limaye A. 2012. Drishti: a volume exploration and presentation tool. SPIE Proceedings Developments in X-Ray Tomography 8 85060X. https://doi.org/10.1117/12.935640

Moat J. \& Smith P. 2007. Atlas of the Vegetation of Madagascar. Royal Botanic Gardens, Kew, Richmond, Surrey.

Myers N., Mittermeier R.A., Mittermeier C.G., da Fonseca A.B. \& Kent J. 2000. Biodiversity hotspots for conservation priorities. Nature 491 (333): 853-858. https://doi.org/10.1038/35002501 
Oatley C.W., Nixon W.C. \& Pease R.F.W. 1966. Scanning electron microscopy. Advances in Electronics and Electron Physics 21: 181-247. https://doi.org/10.1016/S0065-2539(08)61010-0

Padial J.M., Miralles A., De La Riva I. \& Vences M. 2010. The integrative future of taxonomy. Frontiers in Zoology 7 (1): 1-14. https://doi.org/10.1186/1742-9994-7-16

Raxworthy C.J. 2003. Introduction to reptiles. In: Goodman S.M. \& Benstead J.P. (eds) Natural History of Madagascar: 934-949. University of Chicago Press, Chicago.

Ritman E.L. 2004. Micro-computed tomography - current status and developments. Annual Review of Biomedical Engineering 6: 185-208. https://doi.org/10.1146/annurev.bioeng.6.040803.140130

Sanger F., Nicklen S. \& Coulson A.R. 1977. DNA sequencing with chain-terminating inhibitors. Proceedings of the National Academy of Sciences 74 (12): 5463-5467.

https://doi.org/10.1073/pnas.74.12.5463

Schindelin J., Arganda-Carreras I., Frise E., Kaynig V., Longair M., Pietzsch T., Preibisch S., Rueden C., Saalfeld S., Schmid B., Tinevez J., White D.J., Hartenstein V., Eliceiri K., Tomancak P. \& Cardona A. 2012. Fiji: an open-source platform for biological-image analysis. Nature Methods 9 (7): 676-682. https://doi.org/10.1038/nmeth.2019

Shear W.A. \& Edgecombe G.D. 2010. The geological record and phylogeny of the Myriapoda. Arthropod Structure \& Development 39: 174-190. https://doi.org/10.1016/j.asd.2009.11.002

Shelley R.M. \& Golavatch S.I. 2011. Atlas of myriapod biogeography. I. Indigenous ordinal and supraordinal distributions in the Diplopoda: Perspectives on taxon origins and ages, and a hypothesis on the origin and early evolution of the class. Insecta Mundi 158: 1-134.

Silvestri F. 1903. Classis Diplopoda. Vol. 1, Anatome. Pars 1a, Segmenta, Tegumentum, Musculi. Della Torre, Portici, Italy.

Tamura K. \& Nei M. 1993. Estimation of the number of nucleotide substitutions in the control region of mitochondrial DNA in humans and chimpanzees. Molecular Biology and Evolution 10: 512-526.

Tamura K., Stecher G., Peterson D., Filipski A. \& Kumar S. 2013. MEGA6: Molecular Evolutionary Genetics Analysis version 6.0. Molecular Biology and Evolution 30: 2725-2729.

https://doi.org/10.1093/molbev/mst197

Tavaré S. 1986. Some probabilistic and statistical problems in the analysis of DNA sequences. Lectures on Mathematics in the Life Sciences 17: 57-86.

Townsend J.P. \& Leuenberger C. 2011. Taxon sampling and the optimal rates of evolution for phylogenetic inference. Systematic Biology 60 (3): 358-365. https://doi.org/10.1093/sysbio/syq097

Verhoeff K. 1932. Diplopoda. In: Verhoeff K. (ed.) Bronns Klassen und Ordnungen des Tierreichs, Bd. 5/II. Akademische Verlagsgesellschaft, Leipzig.

Waeber P.O., Wilmé L., Mercier J.R., Camara C. \& Lowry II P.P. 2016. How effective have thirty years of internationally driven conservation and development efforts been in Madagascar? PloS One 11 (8): e0161115. https://doi.org/10.1371/journal.pone.0161115

Wells N.A. 2003. Some hypotheses on the Mesozoic and Cenozoic paleoenvironmental history of Madagascar. In: Goodman S.M. \& Benstead J.P. (eds) Natural History of Madagascar: 16-34. University of Chicago Press, Chicago.

Wesener T. 2009. Unexplored richness: discovery of 31 new species of giant pill-millipedes endemic to Madagascar, with a special emphasis on microendemism (Diplopoda, Sphaerotheriida). Zootaxa 2097: $1-131$. 
Wesener T. 2014a. Redescription of Polyzonium malagassum, a new synonym of Rhinotus purpureus (Pocock, 1894), with notes about the occurrence of the order Polyzoniida on Madagascar (Diplopoda). Zootaxa 3790 (4): 587-594. https://doi.org/10.11646/zootaxa.3790.4.7

Wesener T. 2014b. First records of the order Siphonophorida from Madagascar and Mauritius (Diplopoda). Revue Suisse de Zoologie 121 (3): 415-423.

Available from https://biodiversitylibrary.org/page/52965457 [accessed 14 Nov. 2017].

Wesener T. 2014c. A new phylogenetic analysis of the Sphaerotheriida (Diplopoda) with a revision of the Australian giant pill-millipedes. Invertebrate Systematics 28 (2): 196-213.

https://doi.org/10.1071/IS13048

Wesener T. 2015. No millipede endemics north of the Alps? DNA-barcoding reveals Glomeris malmivaga Verhoeff, 1912 as a synonym of G. ornata Koch, 1847 (Diplopoda, Glomerida, Glomeridae). Zootaxa 3999 (4): 571-580. https://doi.org/10.11646/zootaxa.3999.4.7

Wesener T. 2016. The giant pill-millipedes, order Sphaerotheriida - An annotated species catalogue with morphological atlas and list of apomorphies (Arthropoda: Diplopoda). Bonn Zoological Bulletin Supplementum 63: 1-104.

Wesener T. \& Sierwald P. 2005. The giant pill-millipedes of Madagascar - Revision of the genus Sphaeromimus. Proceedings of the California Academy of Science 56: 557-599.

Wesener T. \& VandenSpiegel D. 2009. A first phylogenetic analysis of giant pill-millipedes (Diplopoda: Sphaerotheriida), a new model Gondwanan taxon, with special emphasis on island gigantism. Cladistics 25: 545-573. https://doi.org/10.1111/j.1096-0031.2009.00267.x

Wesener T. \& Wägele J.W. 2008. The giant pill-millipedes of Madagascar: revision of the genus Zoosphaerium (Myriapoda, Diplopoda, Sphaerotheriida). Zoosystema 30 (1): 5-82.

Wesener T., Enghoff H. \& Sierwald P. 2009a. Review of the Spirobolida on Madagascar, with descriptions of twelve new genera, including three genera of 'fire millipedes' (Diplopoda). Zookeys 19: 1-128. https://doi.org/10.3897/zookeys.19.221

Wesener T., Enghoff H., Hoffmann R.L., Wägele J.W. \& Sierwald P. 2009b. Revision of the endemic giant fire millipedes of Madagascar, genus Aphistogoniulus (Diplopoda: Spirobolida: Pachybolidae). International Journal of Myriapodology 2 (1): 15-52. https://doi.org/10.1163/187525409X462403

Wesener T., Raupach M.J. \& Sierwald P. 2010. The origins of the giant pill-millipedes from Madagascar (Diplopoda: Sphaerotheriida: Arthrosphaeridae). Molecular Phylogenetics and Evolution 57 (3): 11841193. https://doi.org/10.1016/j.ympev.2010.08.023

Wesener T., Köhler J., Fuchs S. \& VandenSpiegel D. 2011. How to uncoil your partner-“mating songs" in giant pill-millipedes (Diplopoda: Sphaerotheriida). Naturwissenschaften 98 (11): 967-975. https://doi.org/10.1007/s00114-011-0850-8

Wesener T., Minh-Tu Le D. \& Loria S.F. 2014. Integrative revision of the giant pill-millipede genus Sphaeromimus, with the description of seven new species (Diplopoda, Sphaerotheriida, Arthrosphaeridae). ZooKeys 414: 67-104. https://doi.org/10.3897/zookeys.414.7730

Wongthamwanich N., Panha S., Sierwald P., Wesener T. \& Thirakhupt K. 2012. A new species of the giant pill-millipede genus Sphaerobelum Verhoeff, 1924 from northern Thailand, with an extensive description and molecular characters (Diplopoda: Sphaerotheriida: Zephroniidae). Zootaxa 3220: 29-43.

Yushkevich P.A., Piven J., Hazlett H.C., Smith R.G., Ho S., James C., Gee J.C. \& Gerig G. 2006. Userguided 3D active contour segmentation of anatomical structures: Significantly improved efficiency and reliability. Neuroimage 31 (3): 1116-1128. https://doi.org/10.1016/j.neuroimage.2006.01.015 
Manuscript received: 2 January 2017

Manuscript accepted: 28 March 2017

Published on: 15 December 2017

Topic editor: Rudy Jocqué

Desk editor: Kristiaan Hoedemakers

Printed versions of all papers are also deposited in the libraries of the institutes that are members of the EJT consortium: Muséum national d'Histoire naturelle, Paris, France; Botanic Garden Meise, Belgium; Royal Museum for Central Africa, Tervuren, Belgium; Natural History Museum, London, United Kingdom; Royal Belgian Institute of Natural Sciences, Brussels, Belgium; Natural History Museum of Denmark, Copenhagen, Denmark; Naturalis Biodiversity Center, Leiden, the Netherlands; Museo Nacional de Ciencias Naturales-CSIC, Madrid, Spain; Real Jardín Botánico de Madrid CSIC, Spain. 